\title{
Wage Inequality and the Location of Cities
}

\author{
Farrokhi, Farid; Jinkins, David
}

Document Version

Accepted author manuscript

Published in:

Journal of Urban Economics

DOI:

10.1016/j.jue.2019.04.004

Publication date:

2019

License

CC BY-NC-ND

Citation for published version (APA):

Farrokhi, F., \& Jinkins, D. (2019). Wage Inequality and the Location of Cities. Journal of Urban Economics, 111, 76-92. https://doi.org/10.1016/j.jue.2019.04.004

Link to publication in CBS Research Portal

\section{General rights}

Copyright and moral rights for the publications made accessible in the public portal are retained by the authors and/or other copyright owners and it is a condition of accessing publications that users recognise and abide by the legal requirements associated with these rights.

Take down policy

If you believe that this document breaches copyright please contact us (research.lib@cbs.dk) providing details, and we will remove access to the work immediately and investigate your claim. 


\section{Wage Inequality and the Location of Cities}

\section{Farid Farrokhi, David Jinkins}

Journal article (Accepted manuscript*)

\section{Please cite this article as:}

Farrokhi, F., \& Jinkins, D. (2019). Wage Inequality and the Location of Cities. Journal of Urban Economics, 111, 76-92. https://doi.org/10.1016/.j.jue.2019.04.004

DOl: 10.1016/j.jue.2019.04.004

* This version of the article has been accepted for publication and undergone full peer review but has not been through the copyediting, typesetting, pagination and proofreading process, which may lead to differences between this version and the publisher's final version AKA Version of Record.

Uploaded to CBS Research Portal: March २०२०

(C) 2019. This manuscript version is made available under the CC-BY-NC-ND 4.0 license http://creativecommons.org/licenses/by-nc-nd/4.0/ 


\section{Accepted Manuscript}

Wage Inequality and the Location of Cities

Farid Farrokhi, David Jinkins

PII:

DOI:

Reference:

To appear in:

Received date:

Revised date:

Accepted date:
S0094-1190(19)30026-9

https://doi.org/10.1016/j.jue.2019.04.004

YJUEC 3166

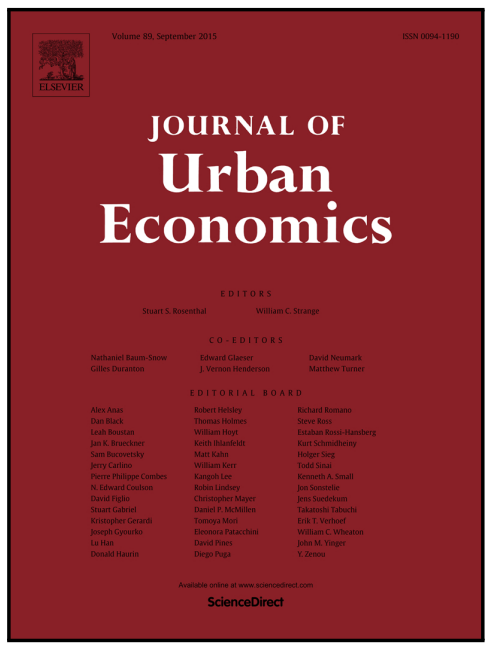

Please cite this article as: Farid Farrokhi, David Jinkins, Wage Inequality and the Location of Cities, Journal of Urban Economics (2019), doi: https://doi.org/10.1016/j.jue.2019.04.004

This is a PDF file of an unedited manuscript that has been accepted for publication. As a service to our customers we are providing this early version of the manuscript. The manuscript will undergo copyediting, typesetting, and review of the resulting proof before it is published in its final form. Please note that during the production process errors may be discovered which could affect the content, and all legal disclaimers that apply to the journal pertain. 


\title{
Wage Inequality and the Location of Cities
}

\author{
Farid Farrokhi ${ }^{1}$ and David Jinkins ${ }^{* 2}$ \\ ${ }^{1}$ Purdue \\ ${ }^{2}$ Copenhagen Business School
}

April 20, 2019

\begin{abstract}
We document that isolated cities have lower skill wage premia in American census data. To explain this correlation and other correlations, between population and wages, we build an equilibrium empirical model that incorporates high and low-skill labor, costly trade, and both agglomeration and congestion forces. Our paper bridges the gap between the economic geography literature which abstracts from inequality, and the spatial inequality literature which abstracts from geography. We find that geographical location explains $16.5 \%$ of observed variation in the skill wage premium across American cities. We use our model to simulate counterfactual trade and technology shocks. Reductions in domestic trade costs benefit both skill groups but low-skill workers benefit more.
\end{abstract}

*An earlier version of this paper was circulated with the title "Trade and Inequality in the Spatial Economy". We gratefully acknowledge support from the Danish Council for Independent Research Grant 8019-00031B, as well as support from the Otto Mønsteds Fond. We thank Sina Smid and Karolina Stachlewska for excellent research assistance. We thank two anonymous referees and the editor Nathaniel Baum-Snow as well as Treb Allen, Jonathan Dingel, Jeff Lin, Tobias Seidal, and participants in seminars at the Asian Meeting of the Econometric Society, Cardiff University, Copenhagen Business School, Copenhagen University, Hitotsubashi University, Indiana Bloomington University, the Nordic International Trade Seminars, the European Trade Study Group, the North American Regional Science Association, Penn State, Purdue, the Society for Economic Dynamics, the Shanghai University of Economics and Finance, and University of Tokyo for helpful suggestions. 


\section{Introduction}

Inequality has long fascinated economists, and growing income inequality has been recently and heatedly discussed in public forums. ${ }^{1}$ This public discussion has been complemented by a number of academic studies highlighting the spatial distribution of wage inequality. We have learned that there is a strong and increasing positive relationship between wage inequality and city size (Baum-Snow and Pavan, 2013; Moretti, 2013; Lindley and Machin, 2014), and that high and low-skill workers are increasingly segregated across cities (Diamond, 2015). In this paper, we add a further attribute of a city to this discussion: spatial position. We first document the relationship between skill wage premia and geographical location across American cities. Then we build and estimate an equilibrium model to study the influence of geography on the skill wage premium, and to study the effects of trade and productivity shocks on welfare and inequality.

Using American census data, we show that the skill wage premium/tends to be smaller in more geographically isolated cities. This result holds across a variety of specifications and weighting strategies. More specifically, the closer a city is to the ocean and the nearer it is to other cities, the larger the difference between the wages of college-educated and high-schooleducated workers tends to be. ${ }^{2}$ For example, Minneapolis is around one standard deviation more isolated than Miami, and has skill wage premia around two standard deviations lower than Miami. In order to explain this correlation together with previously documented facts on population and wages, we develop an estimable equilibrium model of domestic trade and inequality.

While our research speaks to several literatures, our primary contribution is in developing an estimable equilibrium model of spatial wage inequality in which geography matters. Following and contributing to the popular debate on inequality, several authors have expanded our understanding of wage and welfare inequality in American data (Baum-Snow and Pavan, 2013; Combes et al., 2012b; Moretti, 2013; Diamond, 2015; Farrokhi, 2018). As a shorthand, we refer to these papers as the spatial inequality literature. To date, the spatial inequality literature has abstracted from geography. Either cities are unable to trade with each other, or able to trade with each other costlessly. In both of these extremes, the geographic location of a city relative to other cities is irrelevant, so questions about the interaction of geography with inequality cannot be addressed. By including costly trade between cities in a model of mobile heterogeneous labor, we can measure the contribution of geography to inequality.

In order to solve an equilibrium model of inequality, we use tools recently introduced to the economic geography literature by Allen and Arkolakis (2014). We follow a growing body of literature estimating structural economic geography models to evaluate the effects of economic policy on migration and welfare (Bartelme, 2018; Desmet et al., 2016; Allen et al., 2016).

\footnotetext{
${ }^{1}$ The literature on the causes of the rise in American wage inequality in the United States is large. For an extensive treatment, see Goldin and Katz (2009). There is also a growing body of literature on consequences of inequality. For example some studies link income inequality to the recent rise of populism in the United States (McCarty et al., 2016), others to adverse health outcomes (Wilkinson and Pickett, 2006).

${ }^{2}$ These concepts will be defined precisely in Section 2.2 .
} 
The economic geography literature as a whole has typically focused on welfare at the aggregate (Krugman, 1991b; Fujita et al., 2001; Fajgelbaum et al., 2018; Monte et al., 2018). ${ }^{3}$ We complement this literature by studying the effects of policy not only on aggregate welfare but also on welfare inequality.

Our modeling approach allows us to fully solve for counterfactual outcomes taking general equilibrium effects into account. In contrast, the spatial inequality literature has often used equilibrium models without solving for equilibrium. Recent spatial inequality contributions employ instrumental variables and equilibrium relationships to identify a handful of parameters of interest (Moretti, 2013; Baum-Snow et al., 2018). This methodology is/sufficient to test alternative hypotheses about sources of inequality, but it limits a researcher's ability to run counterfactual policy experiments. The closest paper in this recent literature to ours is Diamond (2015), who estimates a rich structural spatial inequality model based on discrete choices of workers over where to live. Diamond (2015) allows for a more flexible specification, while we adopt a more stylized model. The advantage of our stylized model is that we can fully solve our model for the equilibrium employment and wages of skill groups across cities at a wide range of counterfactual parameter values.

In our model, we have a continuum of locations. Bilateral trade costs characterize the geography of these locations. In each location, there are immobile landlords, immobile firms, and perfectly mobile workers. Workers come in two types, high-skill and low-skill, and each worker has an idiosyncratic utility from living in each location. A worker decides where to live taking prices and wages as given. A firm also takes local wages as given, and produces a tradeable good using high-skill and low-skill labor as inputs. The key difference between high and low-skill workers is that high-skill workers benefit more from agglomeration. ${ }^{4}$ In equilibrium, the welfare of marginal workers in each skill group equalizes across space.

We require a model that generates higher skill wage premia in less remote cities. We add two critical features to a quantitative economic geography model in the style of Allen and Arkolakis (2014) to deliver the required relationship. These two features are stronger agglomeration forces for high-skill workers, and heterogeneous location preferences. The intuition behind this interaction can be described in a few sentences. Consider a city near other cities, a centrallylocated city. Its access to cheap tradeable goods and nearby markets make this city attractive to live in. This leads the city, all else equal, to have a relatively high population of both high and low-skill workers compared with a remote city. Due to agglomeration forces, high-skill workers are relatively more productive in the centrally-located city. If the ratio of high to low-skill wages in the centrally-located city were the same as in the remote city, firms would demand a larger ratio of high to low-skill workers in the centrally-located city. In order for the demand for high-

\footnotetext{
${ }^{3}$ One notable exception is Fujita and Thisse (2006), which focuses on inequality and costly trade in an international trade context with only two regions and only high-skill workers mobile. In addition, Fajgelbaum and Gaubert (2018) characterize optimal spatial policy in a setting with trade and skill groups where they compare the observed concentration of skill compared to the efficient outcome in the United States.

${ }^{4}$ Davis and Dingel (2019) microfound a mechanism for this assumption related to complementary between idea exchange and ability.
} 
skill labor to equal its supply, in equilibrium the high to low-skill wage ratio must be higher in the centrally-located city. Because location preferences matter, high-skill workers elsewhere do not fully arbitrage away the higher wages in the centrally-located city.

We interpret the American census data in 2000 as the equilibrium outcome of our model, and we use Core Based Statistical Areas as our cities or geographical units of observation. We estimate our model parameters using equilibrium relationships that describe labor supply and demand across these cities. In addition, we estimate costs of trading goods between cities in a similar way as in Allen and Arkolakis (2014).

We use our estimated model to perform several quantitative exercises. To be clear, our primary contribution is to clarify mechanisms that can generate the patterns of skill wage premia we observe across space. As is standard in the quantitative economic geography literature, our estimates rely on the structure of our stylized model. With that caveat, the exercises we perform help us understand the implications of the mechanisms in our model. First, we use our estimated amenities, productivities, and trade costs to decompose the variation in observed wage premia across American cities. We find that geographical position explains $16.5 \%$ of the variation in skill premia across cities. In addition, we simulate the model equilibrium when domestic trade costs change. We find that reductions in domestic trade costs benefit both types of labor, but low-skill labor gains more than high-skill labor. This result is in contrast to a number of papers that study the effects of international trade on inequality (Antràs et al., 2006; Hummels et al., 2014). ${ }^{5}$ In our exercise, better trading infrastructure tends to spread out the population in the United States so that high-skill workers lose some of their agglomeration advantage over low-skill workers. The negative effect of trade on the skill wage premium in the international context is reversed when labor is mobile in the presence of agglomeration economies in the national context. ${ }^{6}$

Lastly, we simulate the equilibrium effects of the rise of Silicon Valley by implementing a counterfactual productivity shock to all cities in California such that our model generates actual changes to the share of high and low-skill population in California between 1980 to 2000. We find that this skill-biased technology shock increased the expected welfare of high-skill workers nationally by $1.3 \%$ and of low-skill workers nationally by $0.3 \%$.

\section{Documenting inequality and geography}

In this section, we describe our data sources, give our definitions of measures of geography and inequality, and present the empirical findings which motivate our modeling exercise.

\footnotetext{
${ }^{5} \mathrm{~A}$ large body of research in international trade has focused on the effect of trade on inequality. The traditional result is the Stolper-Samuelson Theorem, which says that trade increases inequality in countries abundant in highskill labor, and decreases inequality in countries abundant in low-skill labor (Davis and Mishra, 2007). Of course, an important part of trade models is the inability of factors to cross borders, so the analogy between our work and the trade literature should not be taken too far.

${ }^{6}$ In recent work Fan (2019) finds that domestic reallocation of labor tends to mitigate the increase in inequality caused by an international trade liberalization.
} 


\subsection{Data sources}

Our empirical section is largely based on the IPUMS 5\% sample of the 2000 American census. In this cut of the data, we use full-time workers older than 24 and younger than 55 with reported income.

We want to compare inequality in different locations. As agglomeration will be an important component of our model, the size of a location will be critical for our analysis. Different authors in the literature have used different regions as units of analysis. For our purposes, a location will be either a Core Based Statistical Area (CBSA) or the non-CBSA part of a census area known as a Public Use Microdata Area (PUMA). As shorthand, we will sometimes refer to these areas as "cities". A CBSA is a set of counties with a high degree of social and economic ties to a central urbanized area as measured by commuting ties (US Census, 2012). PUMAs are drawn to completely cover the United States. In order to comply with census disclosure rules, each PUMA contains between 100,000 and 300,000 residents. By including the non-CBSA parts of PUMAs in our analysis, we widen the scope of our study to the entire continental United States.

In addition to the IPUMs data, we need information on the geographical position of each location as well as information on trade flows between locations. We use geographical position data from the Missouri Census Data Center. For trade flows we use publicly available data from the U.S. Commodity Flow Survey (CFS). Our data on trade flows is from 2007, as this is the first year in which data are available at the required level of disaggregation. The 2007 CFS covers business establishments with paid employees in mining, manufacturing, wholesale trade, and selected retail and services trade industries. In the survey, a total sample size of approximately 102,000 establishments are selected from a universe of 754,000 establishments. For further discussion of data sources and manipulation, see Appendix A.

\subsection{Location specific variables}

We calculate the ratio of high-skill to low-skill wages across cities. Skill is unobservable, so we follow the literature in comparing the wages of workers with a 4-year college degree to workers with only a high-school degree. We calculate this skill wage premium using the method described in Acemoglu and Autor (2011). This method flexibly controls for differences in the distribution of experience and gender across cities. First we calculate the total hours worked nationally by gender and five levels of experience (up to 9 years, 10-19 years, 20-29 years, 30-39 years, and 40 and above). We then regress log wages of full-time workers separately in each city on a gender dummy, a set of education dummies, race dummies, a quadratic in experience, and all interactions between the education dummies, gender dummy, and experience. Using our regression estimates, we predict wages in each city for only whites in cells of gender, experience, and education level. We then use the midpoint for each experience group to construct wage predictions for each cell. For example, we create a wage prediction in Atlanta for a white high school educated woman with 5 years of experience, for a white college educated man with 15 years of experience, and so on. We then use the national hours worked by each gender and 
experience cell as weights along with our predicted log wages to calculate the average log wage by city for each education level. Finally we subtract our average log wage for high school graduates from the average log wage for 4-year college graduates in each city. This is the skill wage premium. ${ }^{7}$

Next we assign to each location several measures of isolation from other locations. None of these simple, atheoretical measures is completely satisfying alone. We simply aim to use these measures of isolation to build a case that geography matters, and motivate our subsequent structural analysis rooted in preferences, production technology, and trade costs. To this end, we assign each location two primary measures of isolation: distance to the ocean and remoteness. ${ }^{8}$ We measure a location's domestic isolation using remoteness, a concept we borrow from the international trade literature. Each location is labeled with a number $i=1 \ldots N$. The distance between location $i$ and location $j$ is $d_{i j}$. The distance we use here is structurally estimated later in this paper, and captures the iceberg trade cost between every pair of locations given the network of transportation infrastructure in the United States. The remoteness of location $i, R e m_{i}$, is the weighted, generalized mean of the distances between location $i$ and all other locations:

$$
\operatorname{Rem}_{i}=\left(\sum_{j} \omega_{j} d_{i j}^{1-\sigma}\right)^{\frac{1}{1-\sigma}}
$$

In words, a location with low transport costs to other locations will have low remoteness. In a standard trade model with a CES demand system, the price index of tradeable goods in location $i$ follows a similar expression, with weights $\omega_{i}$ related to economic size, and $\sigma$ interpretable as the elasticity of substitution in utility of differentiated goods. We set $\omega_{j}$ to the population of location $j$, and set $\sigma=4$, following recent estimates in the international trade literature (Broda and Weinstein, 2006; Simonovska and Waugh, 2014).

In addition, we use distance from coastlines to proxy for a location's isolation from international trade. ${ }^{9}$ We measure nearest distance to the ocean as the crow flies using data from Natural Earth. ${ }^{10}$ These data come at a very fine level of disaggregation. To aggregate up to the level of our locations, we assign each location the mean distance to the ocean within its borders. 11

Table 1 reports descriptive statistics, and Figure 1 shows how our measures vary across

\footnotetext{
${ }^{7}$ Our results are robust to alternative measures of wages such as a direct measure of mean log hourly wage as well as log wage residuals obtained from regressing log hourly wage against gender, experience, and race. Our results are also robust to defining a high-skill worker as a worker with 4 years of college or more, and low-skill as all other workers.

${ }^{8}$ To be clear here about terminology, remoteness is one specific measure of isolation. By isolation, we mean aggregated distance from economically important locations.

${ }^{9}$ Coşar and Fajgelbaum (2016) show how distance from the ocean affects trade patterns within a country.

${ }^{10}$ Natural Earth is a free source of physical geographical data in the public domain maintained by the North American Cartographic Information Society. More information at naturalearthdata.com .

${ }^{11}$ Our data comes projected in spherical coordinates. For ease of interpretation, we convert our spherical distances to approximate kilometers using the rule of thumb that one spherical degree in the United States is approximately equal to $100 \mathrm{~km}$. All of our analysis is in logarithms, so scaling errors will only affect the constant.
} 
the United States. The borders in this map are the intersection of PUMAs and CBSAs, but are colored based on the geographical unit of analysis described in Section 2.1. Remoteness is highest in the North and North-West of the United States. Distance from the ocean is highest in the Center-North of the United States. ${ }^{12}$ The skill wage premium is higher in the parts of the country which are less isolated and have higher population.

Below, we report reduced-form correlations in our data to motivate that the geographical position of a city matters for the skill wage premium there. In Section 5, we will use a structurally-estimated price index to quantify precisely how much of the observed variations in skill premium can be explained by geography.

\begin{tabular}{lcccc}
\hline \hline Statistic & Mean & Std Dev & Min & Max \\
\hline Distance from coast & 533 & 346 & 0.39 & 1586 \\
Remoteness & 1.30 & 0.18 & 0.91 & 1.89 \\
Population & $57.48 \mathrm{k}$ & $223.96 \mathrm{k}$ & 410 & $4.75 \mathrm{~m}$ \\
Skill wage premium & 1.40 & 0.09 & 1.15 & 1.83 \\
\hline Worker-level observations & $3.06 \mathrm{~m}$ & & & \\
Location-level observations & 1267 & & \\
\hline \hline
\end{tabular}

Notes: Following Acemoglu and Autor skill wage premium is calculated based on predicted wages, and we restrict our sample to high-school graduates and college graduates.

Table 1: Data summary statistics

\footnotetext{
${ }^{12}$ State borders can sometimes be seen in our measures of remoteness and distance from the coast. This is because one of our measures of geographical location, the PUMA, is always contained within a state, and our other measure, the MSA, is made up of counties which are always contained within a state. Thus the areas we are averaging over often end at state borders. Continuous variation appears, therefore, to stop at the borders of states. For example, the border of Montana and the Dakotas can be clearly seen in the distance from the coast map. This is because Montana is on average closer to the ocean than the Dakotas.
} 


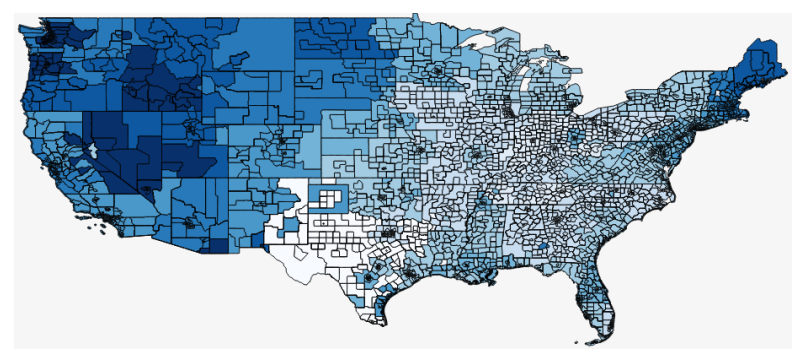

(a) Remoteness

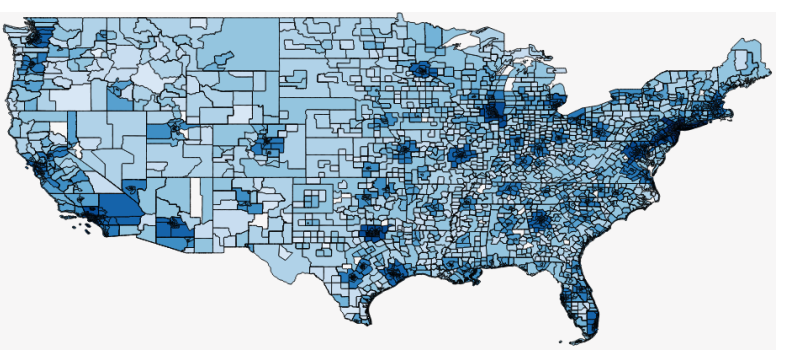

(c) Population

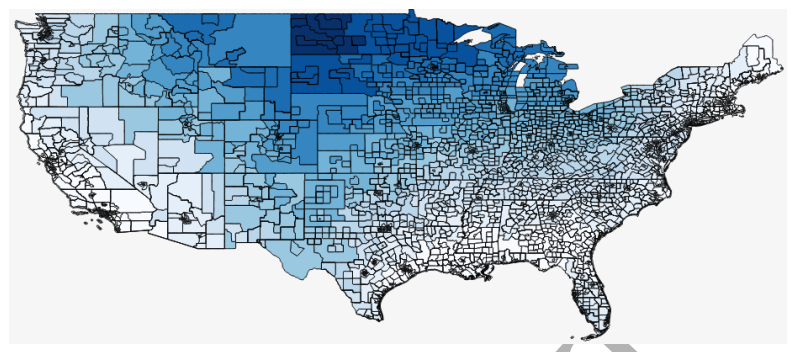

(b) Distance from Coast

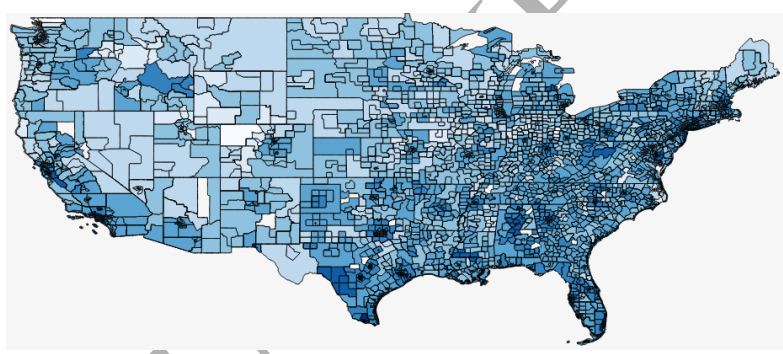

(d) Skill Wage Premium

Figure 1: Locations colored by attribute

\subsection{Skill premium and measures of geography}

We document the covariance of our measures of geography with the skill premium. The literature has documented that wages, the skill wage premium, and the skill employment ratio are all highly and positively correlated with population (Baum-Snow and Pavan, 2013; Moretti, 2013; Lindley and Machin, 2014). In Appendix B we confirm all these well-established facts in our data. Below we add our measures of geography to regressions of individual-level wages and city-level skill premia on population.

Individual-level observations. Table 2 reports the results from regressing individual-level wages against city-lèvel rémoteness allowing for different slopes across high-school and college graduates. We control for individuals' characteristics including gender, race, and years of experience. We include) city population or city population of college graduates as well as state fixed effects across our specifications. Three findings stand out. First, remoteness is negatively correlated with wages. Second, controlling for other variables, wages of college graduates compared to high-school graduates fall more with remoteness. This finding suggests that, after controlling for other observed characteristics, college graduates benefit from a higher skill premium in less remote cities. Third, controlling for city population (or city population of college graduates) lowers the magnitude and statistical significance of the remoteness coefficient.

City-level observations. Columns (1)-(4) of Table 3 report estimates from city-level regressions of the skill wage premium on our measures of geography. Columns (5)-(6) report estimates of regressions of population measures against remoteness. We weight all regressions by population, because our dependent variable is itself composed of data means. Removing these weights 
does not affect the signs or statistical significance of our estimates. We report results from additional specifications in Appendix B.

In columns (1)-(4), we find that locations that are more remote within the United States or more distant from coastlines appear to have a lower skill wage premium. This relationship is statistically significant in all regressions, but it drops in absolute value, from 0.167 to 0.074 , when population is controlled for. Results remain the same when we replace population with college population. The effect of geography on the skill wage premium is mitigated when population is controlled for. In columns (5)-(6), we find that remoteness is negatively correlated with population and with college population across cities. This negative correlation together with the positive association between city size and the skill wage premium are consistent with a hypothesis in which remoteness affects the skill wage premium through its effect on population.

To summarize our empirical findings, the regressions above demonstrate that the more isolated a city is, the lower is its skill wage premium. This relationship holds across a wide range of specifications. In addition, the strength of the relationship between remoteness and the skill wage premium is smaller in magnitude and less statistically significant when we control for population (or college population).

In the next section, we develop a framework to interpret these empirical regularities. Our model features agglomeration forces which are stronger for high-skill workers than they are for low-skill workers. Thus, the relative productivity of high-skill to low-skill workers is higher in larger cities. Due to trade costs, remote cities are also ceteris paribus more expensive to live in, and therefore have lower populations. Intuitively, these model features will explain our empirical findings that the skill premium is higher in less remote cities, and that this effect is mediated by city size.

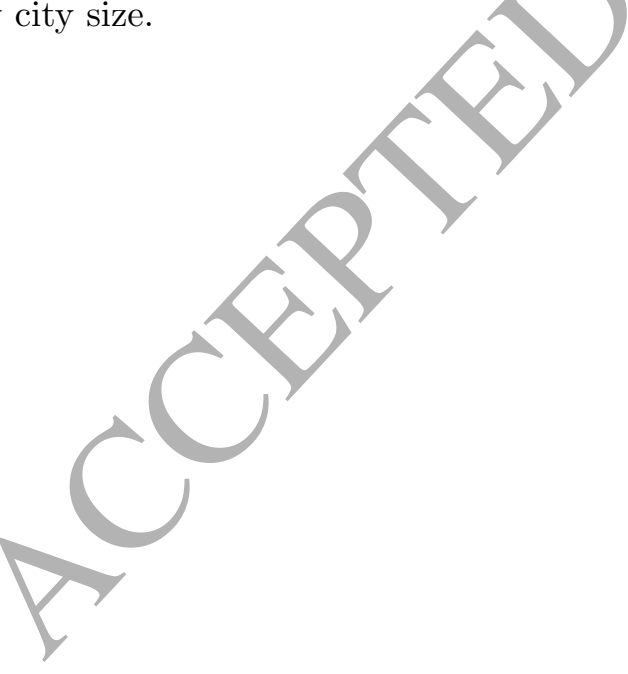


Dependent variable: Log wage of individual workers

(1)

(2)

(3)

(4)

(5)

(6)

(7)

Log remoteness

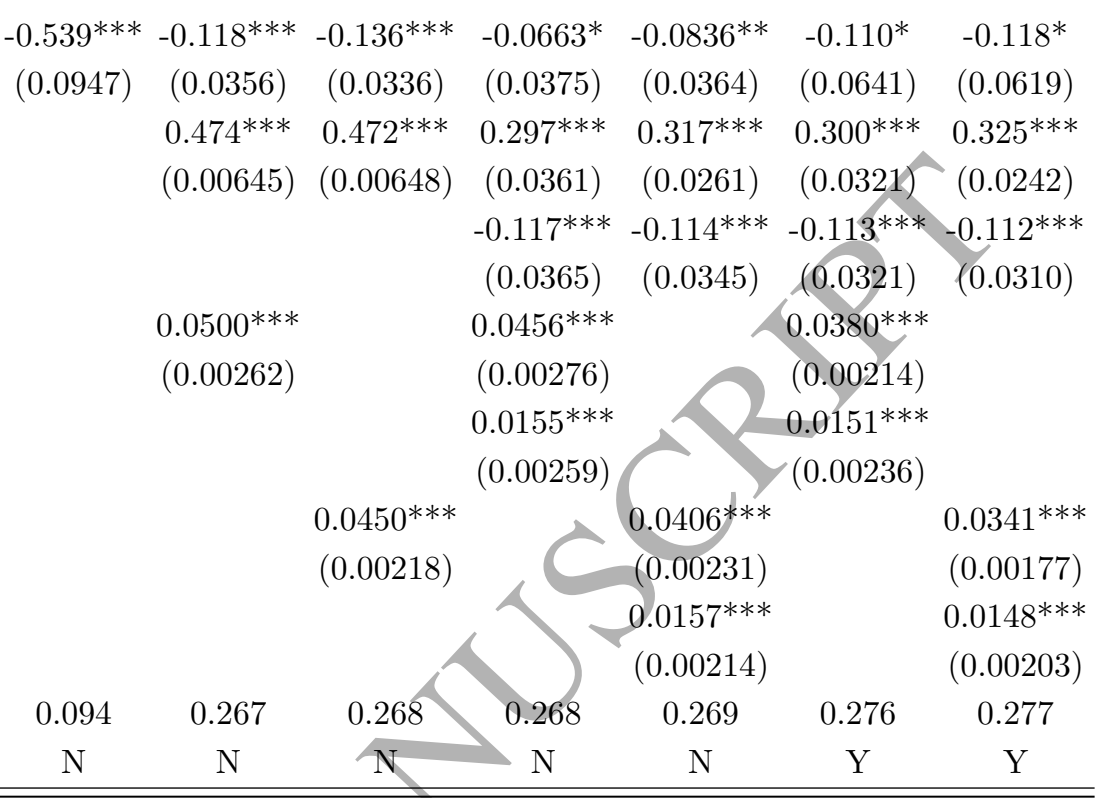

College

College X Log remoteness

Log population

$0.0500^{* * *}$

College X Log population

Log College population

College X Log College population

R-squared

$\mathrm{N} \quad \mathrm{N}$

N

Notes: Standard errors, clustered at city level, are reported in parentheses. In all regressions, there are 3,050,723 observations, we weight individuals based on census sampling weights, and we include individual-level gender and race dummies, a cubic polynomial of years of experience, and state fixed effects. $* * * \mathrm{p}<0.01, * * \mathrm{p}<0.05, * \mathrm{p}<0.1$.

Table 2: Wages and remoteness at the level of individual workers

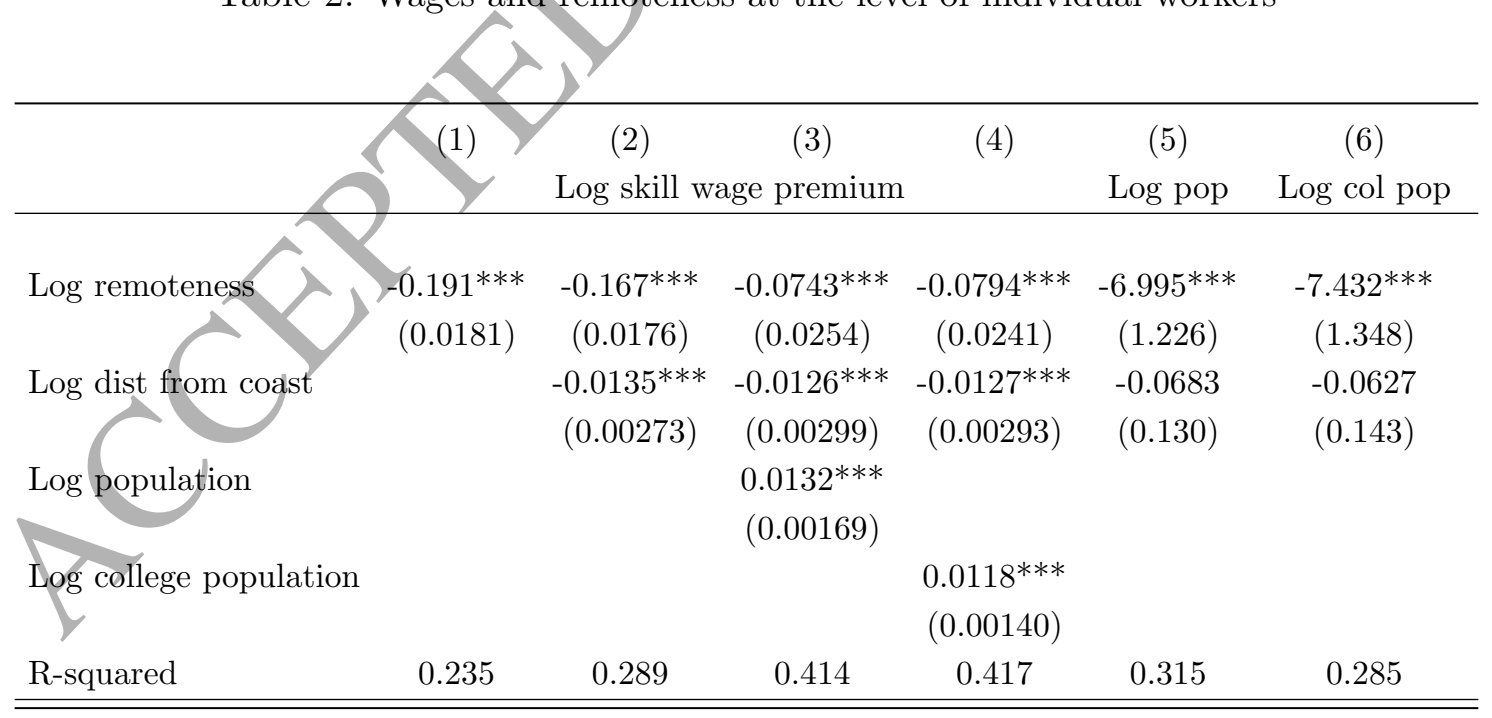

Notes: In all regressions, there are 1267 observations, and we assign population weights to observations. Robust standard errors are reported in parentheses.

$* * * \mathrm{p}<0.01, * * \mathrm{p}<0.05,{ }^{*} \mathrm{p}<0.1$.

Table 3: Skill premium vs geography measures at the level of cities 


\section{Theory}

To explain the empirical relationships documented in the previous section, we build a model that incorporates high- and low-skill labor, costly trade, and both agglomeration and congestion forces. The model helps us examine the equilibrium responses of inequality to shocks that stem from trade or technology.

\subsection{Setup}

The model is static, with a continuum of locations $j \in J$, a continuum of high-skill workers labeled as $H$, and a continuum of low-skill workers labeled as $L$. The set of locations $J$, and the total population of skill groups, $N_{L}$ and $N_{H}$, are given. Workers can choose to reside and work in any single location. Firms in each location produce a location-specific variety of a tradeable final good using the two types of labor as inputs into a constant elasticity of substitution production function. Each location produces a single tradeable location-specific final good. Consumers cannot perfectly substitute across these location-specific final goods. That is, trade is Armington. Both workers and firms are price takers in perfectly competitive markets.

\subsubsection{The worker's problem and labor supply}

The utility of worker $\omega$ in skill group $s$ in location $i$ is a Cobb-Douglas combination of a bundle of tradeable goods, $Q_{\omega}(i)$, and residential lard use, $Z_{\omega}(i)$, augmented with utility from local amenities, $\bar{u}_{s}(i)$, and location preference shocks, $\varepsilon_{\omega}(i)$,

$$
U_{\omega}(i)=\left(\frac{Q_{\omega}(i)}{\delta}\right)^{\delta}\left(\frac{Z_{\omega}(i)}{1-\delta}\right)^{1-\delta} \bar{u}_{s}(i) \varepsilon_{\omega}(i) .
$$

Here, $\delta \in(0,1)$ is the share of expenditures on tradeables. ${ }^{13}$ The tradeable goods are differentiated by the location of production. The bundle $Q(i)$ aggregates quantities of consumption in location $i$ from goods produced in $j, q(j, i)$, under a constant elasticity of substitution $\sigma>0$,

$$
Q(i)=\left[\int_{J} q(j, i)^{\frac{\sigma-1}{\sigma}} d j\right]^{\frac{\sigma}{\sigma-1}}
$$

A worker with skill $s$ who resides in location $i$ earns wages $w_{s}(i)$, and faces the following budget constraint,

$$
w_{s}(i)=C(i) Z(i)+\int_{J} p(j, i) q(j, i) d j
$$

\footnotetext{
${ }^{13}$ While housing services is usually estimated to be a weak necessity good (Aguiar and Bils (2015) report an income elasticity of 0.92 for housing), for simplicity we follow the recent spatial inequality literature in assuming constant expenditure shares (Moretti, 2013; Diamond, 2015).
} 
where $C(i)$ is price per unit of housing in $i$, and $p(j, i)$ is price of good $j$ in destination $i$. While the system of preferences is homothetic, we capture potential heterogeneity across skill groups by letting them value local amenities differently. The idiosyncratic preference shock, $\varepsilon$, is independent across workers and locations, and follows a Fréchet distribution, $\operatorname{Pr}(\varepsilon \leq x)=$ $\exp \left(-x^{-\theta}\right)$, where $\theta$ governs the dispersion of the location preference shocks.

A worker has two decisions to make. She decides where to live, and how much to consume. Given a choice of location, the second problem is standard. Utility maximization implies that a worker spend $\delta$ share of her income on tradeable goods and the rest on housing. A worker of type $s$ in location $i$ spends $x_{s}(j, i)$ on goods produced in $j$,

$$
x_{s}(j, i)=\left[\frac{p(j, i)}{P(i)}\right]^{1-\sigma} \delta w_{s}(i)
$$

where $P(i)$ is the CES price index of tradeables,

$$
P(i)=\left[\int_{J} p(j, i)^{1-\sigma} d j\right]^{\frac{1}{1-\sigma}}
$$

Land is owned by immobile landlords who receive housing rents as their income, and like local workers, decide how much of each good and residential land to consume. The supply of residential land, denoted by $\bar{Z}(i)$, is inelastically given. The land market clearing condition pins down the price per unit of housing,

$$
C(i)=\frac{1-\delta}{\delta \bar{Z}(i)}\left(n_{L}(i) w_{L}(i)+n_{H}(i) w_{H}(i)\right)
$$

where $n_{s}(i)$ denotes the population of skill group $s$ in location $i$. The price index in location $i$, combines prices of tradeable goods and of housing, given by $P(i)^{\delta} C(i)^{1-\delta}$. Total income in location $i$, equals total wages plus housing rents, given by $\frac{1}{\delta}\left(n_{L}(i) w_{L}(i)+n_{H}(i) w_{H}(i)\right)$.

The second decision a worker makes is where to live. A worker $\omega$ with skill level $s$ faces the following discrete choice problem of where to reside:

$$
\max _{i \in J} \frac{w_{s}(i)}{P(i)^{\delta} C(i)^{1-\delta}} \bar{u}_{s}(i) \varepsilon_{\omega}(i)
$$

Using the properties of the Fréchet distribution, the supply of type $s$ labor in location $i$ relative to $j$ is given by:

$$
\frac{n_{s}(i)}{n_{s}(j)}=\left(\frac{w_{s}(i) \bar{u}_{s}(i) /\left(P(i)^{\delta} C(i)^{1-\delta}\right)}{w_{s}(j) \bar{u}_{s}(j) /\left(P(j)^{\delta} C(j)^{1-\delta}\right)}\right)^{\theta} .
$$

The elasticity of relative labor supply to relative wages equals $\theta$. The variance of preference shocks across locations is decreasing in $\theta$. When $\theta$ is large, unobserved location preferences are similar across locations. Thus, small changes to wages, prices, or amenities induce large movements of workers. That is, the supply curve of workers to a location is flat. When $\theta$ is 
small, workers have widely varying preferences over locations, so that large changes in wages, prices, or amenities are necessary to induce movement.

We define the welfare index, denoted by $W_{s}$, for population of skill $s$ :

$$
W_{s} \equiv\left[\int_{j \in J}\left(\frac{w_{s}(j) \bar{u}_{s}(j)}{P(i)^{\delta} C(i)^{1-\delta}}\right)^{\theta} d j\right]^{\frac{1}{\theta}}
$$

This index is proportional to the expected welfare of a worker of type $s$ before she draws her location preferences. ${ }^{14}$ The share of workers of type $s$ in location $i$ is given by:

$$
\frac{n_{s}(i)}{N_{s}}=\left(\frac{w_{s}(i) \bar{u}_{s}(i) /\left(P(i)^{\delta} C(i)^{1-\delta}\right)}{W_{s}}\right)^{\theta}
$$

If a location offers higher wages, better amenities, lower prices of tradeables, and lower housing rents, it will attract more population, with the extent of the relationship governed by $\theta$.

\subsubsection{The firm's problem and labor demand}

Each location has a measure one of homogeneous firms with a CES production under constant returns to scale,

$$
A(i)\left[\beta_{H}(i) n_{H}(i)^{\frac{\rho-1}{\rho}}+\beta_{L}(i) n_{L}(i)^{\frac{\rho-1}{\rho}}\right]^{\frac{\rho}{\rho-1}},
$$

where $A(i)$ is total factor productivity in location $i . \quad \rho>0$ is the elasticity of substitution between high- and low-skill workers. $\beta_{H}(i)>0$ and $\beta_{L}(i)>0$ are factor intensities. We incorporate agglomeration forces by distinguishing two sources of productivity externalities. First, we specify total factor productivity as:

$$
A(i)=\bar{A}(i) n(i)^{\alpha}
$$

with $\alpha>0$. This agglomeration force changes productivity of both low and high-skill workers. A standard Krugman-type economic geography model with monopolistic competition and free entry generates the same relation through an endogenous measure of firms, with the exact relation if $\alpha \neq 1 /(1+\sigma) .{ }^{15}$

In addition, the empirical literature on urban and labor economics substantiates that agglomeration forces are stronger for high-skill workers. ${ }^{16}$ On the theoretical side, the literature

\footnotetext{
${ }^{14}$ To get the expected welfare, we must multiply $W_{s}$ by $\Gamma\left(1+\frac{1}{\theta}\right)$ where $\Gamma$ is the gamma function. This scaling term depends only upon $\theta$, an exogenous preference parameter.

${ }^{15}$ The literature has considered alternate sources of aggregate productivity externalities, for example the sorting of firms as in Gaubert (2018) and Ziv (2017).

${ }^{16}$ For example, Glaeser and Resseger (2010) find that "productivity increases with area population for skilled places, but not for low-skill places," and Bacolod et al. (2009) find that workers with stronger cognitive skills experience stronger agglomeration. See Gould (2007), Matano and Naticchioni (2011), and Combes et al. (2012a) for more details on stronger agglomeration gains for workers with higher skills and wages.
} 
explains this fact by modeling spillovers through the exchange of ideas within high-skill workers (Davis and Dingel, 2019). To capture this mechanism in our empirical model, we let high-skill worker's productivity covary positively with the population of high-skill workers in a location,

$$
\begin{aligned}
\beta_{H}(i) & =\bar{\beta}_{H}(i) n_{H}(i)^{\varphi} \\
\beta_{L}(i) & =\bar{\beta}_{L}(i)
\end{aligned}
$$

where $\varphi>0$ governs the agglomeration advantage that is specific to high-skill workers. By arnormalization, we assign no further agglomeration benefit to low-skill labor. By cost minimization, the unit cost of production equals

$$
\frac{\nu(i)}{A(i)}, \text { where } \nu(i)=\left[\beta_{H}(i)^{\rho} w_{H}(i)^{1-\rho}+\beta_{L}(i)^{\rho} w_{L}(i)^{1} f^{\rho}\right]^{\frac{1}{1-\rho}}
$$

The share of spending of producers on high-skill workers, denoted by $b(i)$, is given by

$$
b(i)=\frac{\beta_{H}(i)^{\rho} w_{H}(i)^{1-\rho}}{\beta_{H}(i)^{\rho} w_{H}(i)^{1-\rho}+\beta_{L}(i)^{\rho} w_{L}(i)^{1-\rho}}
$$

Lastly, as markets are perfectly competitive, price equals marginal cost. Let $d(i, j)$ be the trade cost of shipping a good from $i$ to $j$. The price of a good produced in location $i$ and consumed in location $j$ is:

$$
p(i, j)=\frac{\nu(i) d(i, j)}{A(i)}
$$

\subsubsection{Spatial equilibrium}

The demand side of the labor market requires that $w_{H}(i) n_{H}(i)=b(i)\left(w_{H}(i) n_{H}(i)+w_{L}(i) n_{L}(i)\right)$. Substituting (10) and (8) into this relation gives us the relative labor demand function

$$
\frac{n_{H}(i)}{n_{L}(i)}=\left(\frac{\bar{\beta}_{H}(i)}{\bar{\beta}_{L}(i)}\right)^{\rho}\left(\frac{w_{H}(i)}{w_{L}(i)}\right)^{-\rho} n_{H}(i)^{\varphi \rho}
$$

On the supply side of the labor market, employment shares described by equation (6) imply

$$
\frac{n_{H}(i)}{n_{L}(i)}=\frac{N_{H}}{N_{L}}\left(\frac{W_{H}}{W_{L}}\right)^{-\theta}\left(\frac{\bar{u}_{H}(i)}{\bar{u}_{L}(i)}\right)^{\theta}\left(\frac{w_{H}(i)}{w_{L}(i)}\right)^{\theta}
$$

A necessary condition for labor market clearing is that skill premia simultaneously satisfy the pairs of relative demand (12) and relative supply (13). Combining, we get:

$$
\frac{w_{H}(i)}{w_{L}(i)}=\left(\frac{W_{H}}{W_{L}}\right)^{\frac{\theta}{\theta+\rho}}\left(\frac{\bar{u}_{H}(i)}{\bar{u}_{L}(i)}\right)^{\frac{-\theta}{\theta+\rho}}\left(\frac{N_{H}}{N_{L}}\right)^{\frac{-1}{\theta+\rho}}\left(\frac{\bar{\beta}_{H}(i)}{\bar{\beta}_{L}(i)}\right)^{\frac{\rho}{\theta+\rho}} n_{H}(i)^{\frac{\varphi \rho}{\theta+\rho}}
$$

Labor market clearing also requires total wages received by all workers to be equal to total 
payments to them, ${ }^{17}$

$$
\frac{w_{H}(i) n_{H}(i)}{b(i)}=\int_{J} \frac{w_{H}(j) n_{H}(j)}{b(j)}\left[\frac{p(i, j)}{P(j)}\right]^{1-\sigma} d j
$$

Equations 14 and 15 describe labor market clearing in relative terms and in levels. Equivalently, equation 15 describes the goods market clearing condition.

A "spatial equilibrium" consists of $w_{H}(i), w_{L}(i), n_{H}(i)$, and $n_{L}(i)$ such that: (1) firms optimize their labor demand, (2) workers optimize their labor supply, (3) markets clear, and (4) the labor allocation is feasible. ${ }^{18}$ This completes our description of the economy.

\subsubsection{Discussion}

Suppose we were to shut down preference heterogeneity, $\theta \rightarrow \infty$. From (14) we see that skill wage premia will be constant across locations. Alternatively, suppose there is no agglomeration advantage for high-skill workers, $\varphi=0$. Then skill premia can vary between destinations only due to exogenous differences in tastes and productivities between skill groups. To have equilibria with endogenously varying skill premia, we need both heterogeneity in unobserved location preferences (finite $\theta$ ), and an agglomeration advantage for high-skill workers $(\varphi>0)$. That is, large cities demand relatively more high-skill workers due to agglomeration, but since unobserved location preferences matter, high-skill workers do not fully arbitrage the wage increase away. ${ }^{19}$

To provide further intuition, suppose trade costs to and from a remote city fall. This shock decreases the price of incoming tradeables, hence the supply of workers to the city rises. In addition, the shock increases outgoing sales, hence labor demand in the city rises. If the employment of low- and high-skill workers increase proportionately, agglomeration advantages will make high-skill workers relatively more productive. That is, firms demand a higher ratio of high to low-skill workers than their relative supply in the city. Equilibrium is restored only by raising skill wage premium in the city.

This relationship between trade costs and skill premia does not depend on exogenous differ-

\footnotetext{
${ }^{17}$ Total wages in location $i$ equal $\frac{w_{H}(i) n_{H}(i)}{b(i)}$, and total income (wages plus rents) equals $\frac{w_{H}(i) n_{H}(i)}{\delta b(i)}$. Both workers and landlords spend $\delta$ share of their income on tradeables and the rest on housing. Thus, total wages in $i$ equal $\int_{J} \delta[$ total income in $j]\left[\frac{p(\ell, j)}{P(j)}\right]^{1-\sigma} d j$.

${ }^{18}$ That is simply $\int_{J} n_{H}(j) d j=N_{H}$ and $\int_{J} n_{L}(j) d j=N_{L}$.

${ }^{19}$ Our model relies on differential agglomeration forces between high and low-skill workers and an upward sloping labor supply curve to generate the observed negative relationship between remoteness and the skill premium. Alternatively, such a relationship could potentially be generated by non-homothetic preferences. In particular, suppose that (poorer) low-skill workers consume a higher share of tradeables and a lower share of housing services. Then, in a spatial equilibrium, low-skill workers would need to be compensated more for living in remote areas, delivering a lower skill premium in remote areas.

Empirically, however, it is high-skill workers that consume a higher share of tradeables and a lower share of housing services. As mentioned in footnote 14, studies typically find housing services to be a slight necessity good, and recent research has found that higher income Americans consume a higher share of tradeables (Hummels and Lee, 2018). Since non-homothetic preferences predict the opposite of the observed relationship between remoteness and the skill premium, by assuming homothetic preferences we may be underestimating the strength of the agglomeration advantage of high-skill workers.
} 
ences across skill groups. The exogenous differences are residuals in the relation between skill employment ratio and skill wage premium in equations of relative demand (12) and relative supply (13). These residuals reflect factors we do not model such as state and local tax incidence, provision of welfare, and non-labor factor endowments.

Our model implies that the spatial distribution of workers contributes to welfare inequality. Specifically, writing the distribution of low-skill labor as a function of that of high-skill labor, and after some algebra, we decompose three forces behind average welfare inequality,

$$
\frac{W_{H}}{W_{L}}=\underbrace{\left(\frac{N_{H}}{N_{L}}\right)^{-\frac{1}{\rho}}}_{\text {aggregate scarcity }} \times \underbrace{\left(N_{H}\right)^{\varphi}}_{\text {aggregate agglom. }} \times \underbrace{\left[\int_{J} \pi(i) d i\right]^{-\frac{\theta+\rho}{\beta \rho}}}_{\text {distributional effect }}
$$

The first term reflects aggregate scarcity of high- to low-skill workers; the second term represents aggregate agglomeration advantage of high-skill workers; and the last term summarizes dispersion forces. ${ }^{20}$ This last term depends on the entire distribution of population which in turn endogenously changes with geography.

\subsection{Solving for spatial equilibrium}

We characterize model equilibria, normalizing wages of high-skill workers such that $\int_{J} w_{H}(j) d j=$ 1. Using equations (8), (9), and (10) we can write $\nu(i)$ as a function of employment, input expenditure share, and wages of high-skill workers:

$$
\nu(i)=\tilde{\nu}(i) w_{H}(i) \text {, where } \tilde{\nu}(i) \equiv\left[\bar{\beta}_{H}(i) n_{H}(i)^{\varphi}\right]^{\frac{\rho}{1-\rho}}[b(i)]^{\frac{-1}{1-\rho}}
$$

In addition, normalizing the land supply to one, we can write housing rents as a function of employment and wages of high-skill workers:

$$
C(i)=\tilde{C}(i) w_{H}(i), \text { where } \quad \tilde{C}(i) \equiv \frac{(1-\delta) n_{H}(i)}{\delta b(i)}
$$

First, replacing the price index of tradeables $P(j)$ from employment share (6) into the goods market clearing condition (15) results in:

$$
\begin{aligned}
& A(i)^{1-\sigma} \nu(i)^{\sigma-1} n_{H}(i) w_{H}(i) b(i)^{-1} \\
& =W_{H}^{\frac{1-\sigma}{\delta}} N_{H}^{\frac{\sigma-1}{\delta \theta}} \int_{J} d(i, j)^{1-\sigma} \bar{u}_{H}(j)^{\frac{\sigma-1}{\delta}} C(j)^{\frac{(\sigma-1)(\delta-1)}{\delta}} n_{H}(j)^{\frac{1-\sigma+\delta \theta}{\delta \theta}} w_{H}(j)^{\frac{\sigma-1+\delta}{\delta}} b(j)^{-1} d j(1
\end{aligned}
$$

${ }^{20}$ Specifically, $\pi(i)=\left(\frac{\bar{\beta}_{H}(i) \bar{u}_{H}(i)}{\bar{\beta}_{L}(i) \bar{u}_{L}(i)}\right)^{\frac{-\theta \rho}{\theta+\rho}}\left(\frac{n_{H}(i)}{N_{H}}\right)^{\frac{\theta(1-\rho \varphi)+\rho}{\theta+\rho}}$ 
Second, substituting the price index of tradeables $P(j)$ from employment share $(6)$ into the CES price formula (4), results in:

$$
\bar{u}_{H}(i)^{\frac{1-\sigma}{\delta}} C(i)^{\frac{(\sigma-1)(1-\delta)}{\delta}} n_{H}(i)^{\frac{\sigma-1}{\delta \theta}} w_{H}(i)^{\frac{1-\sigma}{\delta}}=W_{H}^{\frac{1-\sigma}{\delta}} N_{H}^{\frac{\sigma-1}{\delta \theta}} \int_{J} d(j, i)^{1-\sigma} A(j)^{\sigma-1} \nu(j)^{1-\sigma} d j
$$

The pair of 19-20 gives us two systems of integral equations. Assuming that trade costs are symmetric, we can reduce the two systems into one using a method from Allen and Arkolakis (2014). If either of integral equations hold along with the following relation, both systems of integral equations must hold:

$$
A(i)^{1-\sigma} \nu(i)^{\sigma-1} n_{H}(i) w_{H}(i) b(i)^{-1}=\lambda \bar{u}_{H}(i)^{\frac{1-\sigma}{\delta}} n_{H}(i)^{\frac{\sigma-1}{\delta \theta}} w_{H}(i)^{\frac{1-\sigma}{\delta}} C(i) \stackrel{(\sigma-1)(1-\delta)}{\delta}
$$

where $\lambda>0$ is a constant.

Relationship with existing models. Our analysis relates to two styles of spatial models. First, as mentioned earlier we extend spatial inequality models by incorporating costly trade between cities. Conversely, we extend empirical models of economic geography by incorporating skill groups. Our model, in particular, nests Allen and Arkolakis (2014) if (i) there is no heterogeneity in location preferences, (ii) there is no agglomeration advantage for high-skill workers, (iii) workers with different skills are perfectly substitutable. That is, if $\varphi=0, \theta=\infty$, and $\rho=\infty .^{21}$

Uniqueness. The standard proof of equilibrium uniqueness in the existing related literature in economic geography depends on a specification that allows logarithmic relationships between a subset of endogenous variables (Allen and Arkolakis, 2014). Our model deviates from such logarithmic relationships. For example, instead of $A=\bar{A} n^{\gamma}$ where one must solve for $n$, we have $A=\bar{A}\left(n_{L}+n_{H}\right)^{\gamma}$ where we must solye for $n_{L}$ and $n_{H}$. Here, the relationship between high-skill population $n_{H}$ and productivity $A$ is not logarithmic. For this reason, the standard proof in this recent literature can not be directly used in our setting. We can show that for the special case in which our model collapses to Allen and Arkolakis, uniqueness is achieved at our preferred parameter estimates. In addition, we have solved our model at our parameter estimates (to be reported in the next section) using different initial values, and found no evidence of multiplicity.

Solution algorithm. We solve our system of integral equations using an iterative method. A feature of gur model is that given exogenous parameters, every endogenous variable can be written as a function of $n_{H}(i)$. Using this feature, our solution algorithm updates our guess for population of high-skill workers $n_{H}(i)$ in each iteration. In checking existence and uniqueness we confirm that these iterations converge to one solution for a wide variety of initial guesses. In Appendix D we describe our solution algorithm in detail.

${ }^{21}$ The way we model congestion is a little different than in Allen and Arkolakis (2014), but our models are isomorphic once the conditions (i), (ii), and (iii) are fulfilled. We interpret the source of congestion as limited land for housing. Allen and Arkolakis are agnostic about the source of congestion, only assuming that amenities are reduced by population. 


\section{Estimation}

In this section we estimate our structural model. Our data consist of four vectors: high and low-skill populations in each location, and high and low-skill wages in each location. Using our model structure, we invert these four vectors of data to recover four vectors of exogenous shifters: high-skill factor intensities $\bar{\beta}_{H}$ (with $\bar{\beta}_{L}=1-\bar{\beta}_{H}$ ), total factor productivity shifters $\bar{A}(i)$, and amenity values for low and high-skill workers $\bar{u}_{L}(i)$ and $\bar{u}_{H}(i)$.

The inversion of the data into these exogenous shifters depend on the matrix of trade costs as well as six key parameters: (i) the high-skill agglomeration advantage $\varphi$, (ii) the elasticity of substitution across skill groups $\rho$, (iii) the labor supply elasticity $\theta$, (iv) the common agglomeration parameter $\alpha,(\mathrm{v})$ the share of expenditures on housing $1-\delta$, and (vi) the elasticity of substitution across goods $\sigma$. We estimate trade costs between American cities in a similar way to Allen and Arkolakis (2014). We calculate housing share, $1-\delta=0.355$, based on the Consumer Expenditure Survey 2000. ${ }^{22}$ We set the elasticity of substitution across goods to $\sigma=4$, in line with the empirical literature using international trade data (Broda and Weinstein, 2006; Simonovska and Waugh, 2014). Following a large literature, we use instrumental variables and equilibrium relationships to estimate the other four parameters (Moretti, 2013; Desmet et al., 2016; Allen et al., 2016).

Since our estimation procedure contains several sequential steps, we present intermediate results directly after we describe intermediate estimation steps. Trade costs are estimated first. Next key elasticities are estimated from equilibrium labor demand and supply relationships. We then invert a set of equilibrium integral equations to recover exogenous location-specific productivities and amenities.

\subsection{Estimation of trade costs}

In many countries, the largest cities are on coastlines or near major rivers. The United States is no exception, with the East and West coasts containing the majority of the population. If domestic trade costs were simply quadratic in distance, then Lebanon, Kansas (with population size of 218) would be the center of gravity in the continental United States. A wide range of geographical features in addition to distance affect the cost of trading between any two locations. It is often easier to go around a mountain even if the geodesic between two locations goes through one. New York and Miami are about as far apart as New York and Lebanon, Kansas, but shipping a container from New York to Miami is cheaper because of the possibility of using a ship. To capture these nontrivial features of geography, we estimate trade costs by using a method from Allen and Arkolakis (2014) which takes geographic features into account.

We provide a short overview here, with more details contained in the original Allen and

\footnotetext{
${ }^{22}$ Specifically, housing expenditures consist of (i) shelter, (ii) utilities, fuels, and public service, (iii) household operations, (iv) housekeeping supplies, and (v) house-furnishings and equipment. We exclude personal insurance and pensions from total expenditures. The share of housing is taken to be 0.40 in Monte et al, 0.42 in Moretti and Diamond, and 0.19-0.25 in Allen and Arkolakis.
} 
Arkolakis paper. There are three steps to the estimation process. In the first step, we use three separate image files each containing a map of the United States. On one of the maps is the road network, on the second is the railway network, and on the last is the waterway network. ${ }^{23} \mathrm{We}$ consider four possible methods for moving goods: road, rail, water, and air. For each of these methods separately, we assign a cost of traveling over each pixel of the relevant image file. Then, we calculate the lowest possible cost of using each method to move goods between all pairs of locations using a fast marching algorithm.

After we finish the first step, we know how much it costs to move goods between any two locations for every method of transport, but only in terms of the units we assigned to that method of transport. We cannot compare the cost of road travel to the cost of water transport because we do not know the exchange rate, as it were, of road travel to water transport. The second step is to use a discrete choice framework and data on trade flows via eách mode between each pair of locations in order to back out these cost ratios. Shippers have idiosyncratic, extreme value distributed costs for each mode of transportation. If a large share of transport is via road, then it must be that road is on average a cheaper mode of transportation.

The discrete choice model will only give us the cost ratio between any two modes of transportation, but we still need to pin down the level of costs. To do so, we use the gravity specification implied by our model. Consistent with our later structural estimation, we set the elasticity of substitution across goods equal to four. Estimating the gravity equation gives the scale of trade costs. With the scaling parameter in Kand, we can then calculate expected trade costs between every pairs of locations.

Our estimates for trade costs are summarized in Table 4. Road, by normalization, has no fixed cost, and according to the estimation, has a mid-level marginal cost. Rail has a significant fixed cost, but lower marginal cost than road transport. Water has both high fixed and marginal cost, reflecting that little shipment within the United States is done by water. Air has a high fixed cost, but a low marginal cost. To be more concrete, we estimate that the average iceberg cost of shipping from Chicago to New York City and the average cost of shipping from Chicago to Fargo, Minnesota are almost the same (1.27 and 1.26 respectively) even though Chicago is closer to Fargo ( 569 miles) than it is to New York City (714 miles) as the bird flies. The highway system connecting Chicago to New York City is both higher quality and more direct.

Readers familiar with Allen and Arkolakis (2014) or Desmet et al. (2016) will notice that our estimates/are quantitatively somewhat different than those of these earlier studies, although the ranking of variable and fixed costs is similar. One reason for the difference is that we set a lower trade elasticity in our structural estimation, $\sigma=4$ rather than $\sigma=9 .^{24}$ Our trade costs are likely higher in absolute terms than in Allen and Arkolakis (2014), as our products are more

\footnotetext{
${ }^{23}$ Following Allen and Arkolakis (2014), we take the road, rail, and water shipping network of the United States as fixed in our counterfactuals. We think of our counterfactuals as pertaining to the medium-run. That is, labor is mobile, but basic productivity, amenities, and the broad outline of the transportation network is fixed.

${ }^{24}$ Regarding the difference between our estimates and those in Allen and Arkolakis (2014), even if we use $\sigma=9$ we get somewhat different results, even though we implement the same algorithm on the same data. We discuss reasons for these differences in Appendix C.
} 
differentiated. ${ }^{25}$

\begin{tabular}{lllll}
\hline \hline & Road & Rail & Water & Air \\
\hline Variable cost & 1.2526 & 1.1165 & 2.1261 & 0.4866 \\
Fixed cost & 0 & 0.9766 & 1.2210 & 1.7748
\end{tabular}

Note: Distance costs between locations for a particular shipment mode are calculated as $\exp ($ variable cost $\times$ distance + fixed cost), where distance is mode-specific and normalized so that the width of the United States is one.

Table 4: Estimated Trade Costs

\subsection{Estimation of labor demand and supply}

\subsubsection{Relative demand and supply}

We estimate the high-skill agglomeration advantage $\varphi$, the elasticity of substitution across skill groups $\rho$, and the labor supply elasticity $\theta$ using the equilibrium conditions (12) and (13) derived in Section 3.1.3. We write these equations in log relative terms as follows,

$$
\begin{aligned}
& \tilde{w}(i)=\tilde{\kappa}+\frac{1}{\theta} \tilde{n}(i)-\tilde{u}(i) \\
& \tilde{n}(i)=-\hat{\tilde{w}}(i)+\rho \varphi \log n_{H}(i)+\rho \tilde{\beta}(i)
\end{aligned}
$$

where

$$
\tilde{n}(i)=\log \left[\frac{n_{H}(i)}{n_{L}(i)}\right], \tilde{w}(i)=\log \left[\frac{w_{H}(i)}{w_{L}(i)}\right], \tilde{\beta}(i)=\log \left[\frac{\bar{\beta}_{H}(i)}{\bar{\beta}_{L}(i)}\right], \tilde{u}(i)=\log \left[\frac{\bar{u}_{H}(i)}{\bar{u}_{L}(i)}\right]
$$

and, $\tilde{\kappa}$ is a constant. 26 Estimating these equations using OLS may be problematic due to correlations between error terms and regressors. In equation (22), the skill employment ratio, $\tilde{n}$, is expected to be higher in locations where the ratio of amenity values for high-skill relative to low-skill, $\tilde{u}$, are greater. This correlation means that OLS presumably underestimates $1 / \theta$. In addition, in equation (23), skill premium, $\tilde{w}$, and high-skill population, $n_{H}$, are presumably higher in locations where the ratio of high-skill to low-skill productivity, $\tilde{\beta}$ are larger. This correlation implies that OLS underestimates $\rho$ and overestimates $\varphi$.

We use instrumental variables to estimate equations (22) and (23). To estimate $\theta$ in the relative supply function (22), we instrument skill employment ratio $\tilde{n}$ using a variable that is meant to exclusively capture shifts from the demand side. We are inspired by a large urban and

\footnotetext{
${ }^{25} \mathrm{~A}$ further technical issue is that $4.7 \%$ of our iceberg trade costs are estimated to be less than one. In the structural estimation below, we normalize trade costs by scaling up all trade costs proportionally until the lowest iceberg trade cost has a value of one.$$
{ }^{26} \tilde{\kappa}=-\frac{1}{\theta} \log \left[\frac{N_{H}}{N_{L}}\left(\frac{W_{H}}{W_{L}}\right)^{-\theta}\right]
$$ 
spatial inequality literature in constructing our exogenous shock using industry-level variation across locations (Bartik (1991); Moretti (2013); Diamond (2015)). Let $d$ index industry, $E_{d}(i)$ be the employment share of industry $d$ in location $i$ with $\sum_{d} E_{d}(i)=1$, and $\frac{N_{H, d}(-i)}{N_{L, d}(-i)}$ be the national skill population share in industry $d$ excluding location $i$ itself. Our instrument is

$$
\sum_{d} E_{d}(i) \log \left(\frac{N_{H, d}(-i)}{N_{L, d}(-i)}\right)
$$

We assume that industry composition only affects the wage premium through its effect on the skill employment ratio, and is uncorrelated with relative amenities. Suppose relative employment of high-skill workers is greater nationwide in certain industries. Then, cities with larger employment shares in those certain industries will have more demand for high-skill relative to low-skill workers. This creates a shift in demand for high-skill workers, which is presumably uncorrelated with supply factors (amenities) in a location.

The exogeneity assumption is that our instrument is uncorrelated with relative amenitiesthe amenities assigned to a location by high-skill workers relative to the amenities assigned to a location by low-skilled workers. In our model, we assume that amenities are immutable features of locations. Our exogeneity assumption would be violated if skill-intensive industries chose to locate in places relatively preferred by skilled workers. We believe that industry location is more driven by other factors such as proximity to markets as in Krugman (1980), proximity to natural resource endowments as in Ellison and Glaeser (1999), or simply historical accident as in Krugman (1991a).

Since we do not have strong priors about what sort of amenities high-skill workers prefer relative to low-skill workers, the exogeneity condition is difficult to test directly. We can however show that the instrument is uncorrelated with a number of different measures of amenity levels. Figure 2 contains scatter plots of the instrument against air pollution, humidity in the summer, temperature in the winter, distance from the coast, log remoteness and the quality of life index described in the following paragraph. ${ }^{27}$ The instrument is uncorrelated with all of these measures except a weak negative correlation with the quality of life index which is only measured for MSAs.

To estimate $\rho$ and $\varphi$ in the relative demand equation (23), we use the residuals of the relative supply equation, $\tilde{u}$, as an instrument for skill premium, $\tilde{w}$. The orthogonality between this instrument and the error terms is based on the assumption that the relative amenity valuations, $\tilde{u}$, are uncorrelated with relative factor intensities, $\tilde{\beta}$. In addition, we instrument high-skill population $n_{H}(i)$ using an extended quality of life index that we borrow from Albouy (2012). ${ }^{28}$ This index is only reported for MSAs. We extend the index to our broader set of geographical units by regressing the index on a large set of observables, and predicting missing values. Our estimates remain virtually the same if we restrict our sample to only MSAs. This quality of life index is by construction uncorrelated with prices and wages in a location, but as Albouy

\footnotetext{
${ }^{27}$ Information on air quality is from US Environmental Protection Agency (2019), and maps of the US by temperature and humidity are from US National Oceanic and Atmospheric Administration (2016).

${ }^{28}$ Specifically, we use Albouy's "adjusted" measure of quality of life.
} 


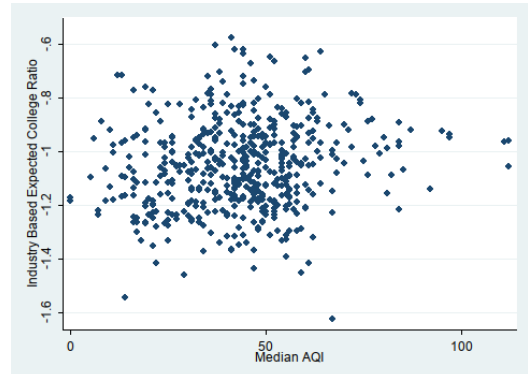

(a)

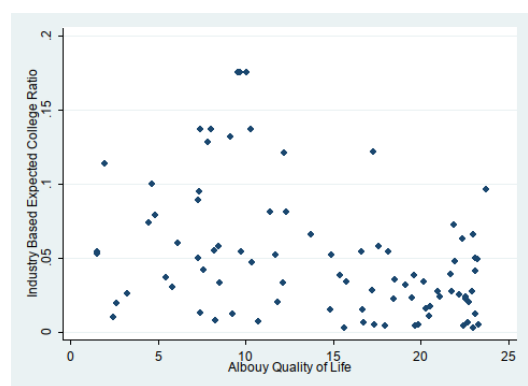

(d)

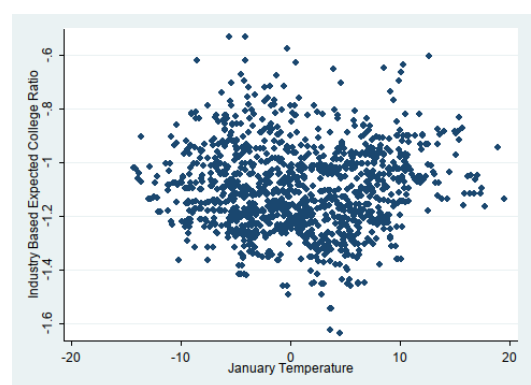

(b)

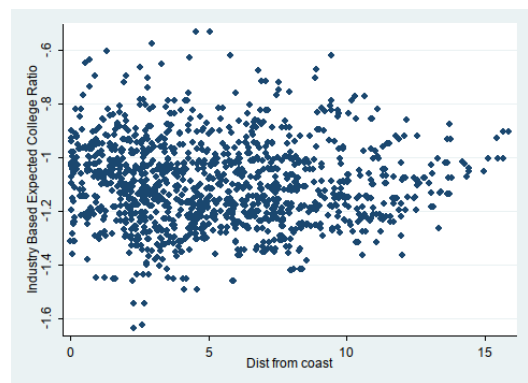

(e)

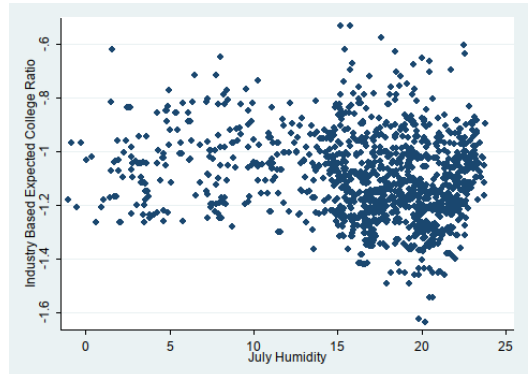

(c)

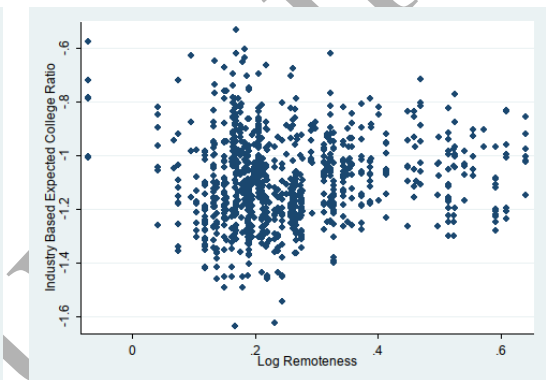

(f)

Figure 2: Industry Skill Instrument vs Amenity Level Measures

shows, it strongly correlates with a wide range of natural and artificial amenities in a location. The orthogonality between this instrument and error terms is based on the assumption that this measure of quality of life is not correlated with relative factor intensity.

Our identification assumption requires that the exogenous relative demand for high-skill workers in a city's production function is not correlated with relative or absolute amenity levels. This exclusion restriction is not implied by our model. It might then be argued, for example, that cities which are attractive to live in are also more productive on average for exogenous reasons such as temperate weather. Such a relationship would only violate our exogeneity assumption if high-skill workers were more productive relative to low-skill workers in cities with temperate weather or some other exogenous amenity. In this respect, the scatter plots in Figure 2 once again support our exclusion restriction, as they show that a measure of the relative demand for skill is uncorrelated with common measures of amenities. Moreover, we find the exogeneity restriction intuitively plausible. It would be coincidental if city-specific features that workers prefer like temperate weather were correlated with the exogenous relative demand for skill. Lastly, it is worth mentioning that our IV estimates of the relative demand equation, which we discuss below, move the OLS estimates in the expected direction.

Estimation results are summarized in Table 5. The Cragg-Donald F-statistics for the first stage strongly reject that the instruments are weak. The more conservative heteroskedacticityrobust Kleibergen-Paap F-statistics are somewhat lower, especially the F-statistic on the labor demand regression of 10.0. For all parameters the IV regressions push the OLS estimates in 
directions consistent with our priors explained above. According to our estimates, the dispersion of location preferences $\theta=\frac{1}{.072}=13.8$, the elasticity of substitution in production between high and low-skill labor $\rho=3.276$, and the agglomeration advantage of high-skill labor $\varphi=$ $0.368 / 3.276=0.112 .{ }^{29}$ In addition, the residuals in equations (22) and (23) give us the exogenous shifters of relative productivities and amenities $\tilde{\beta}$ and $\tilde{u}$.

\begin{tabular}{lcccc}
\hline \hline & \multicolumn{2}{l}{$\log$ skill premium, Eq. (22) } & \multicolumn{2}{l}{ log employment ratio, Eq. (23) } \\
& OLS & IV & OLS \\
\hline log employment ratio & $0.055^{* * *}$ & $0.072^{* * *}$ & & \\
log skill premium & & & -0.092 & $-3.276^{* * *}$ \\
log high-skill population & & & $0.182^{* * *}$ & $0.368^{* * *}$ \\
constant & $0.416^{* * *}$ & $0.426^{* * *}$ & $-2.568^{* * *}$ & $-3.389^{* * *}$ \\
\hline 1st stage F (CD) & & 4956 & & 100.7 \\
1st stage F (KP) & & 1123 & 10.0 \\
\hline
\end{tabular}

Note: Robust standard errors are in parentheses. Number of observations is 1267 across all columns. All observations are weighted by city population. ${ }^{* *} \mathrm{p}<0.01,{ }^{* *} \mathrm{p}<0.05,{ }^{*} \mathrm{p}<0.1$.

Table 5: Estimating relative labor demand and supply

\subsubsection{Productivities and amenities}

With key parameter estimates in hand, we next solve for total factor productivity $A(i)$ and highskill base utility from amenities $\vec{u}_{H}(i)$. Similar to spatial quantitative models, the identification of these shifters relies on the combination of observed population and wages across cities.

To invert the population and wage data, we use equilibrium integral equations derived by our model. Our estimation procedure consists of two steps:

Step 1. We first estimate total factor productivity $A$ inclusive of spillovers as well as high-skill

\footnotetext{
${ }^{29}$ Our estimate of the elasticity of substitution between high-skill and low-skill labor $\rho$ is a bit higher than estimates reported by the literature. In a literature review, Katz et al. (1999) reports values for this elasticity between 1.40 to 1.70. Ciccone and Peri (2006) come up with estimates between 1.3 and 2, Diamond (2015) estimates $\rho=1.6$, and Card (2009) finds that $\rho=2.5$. There is a shorter literature estimating the dispersion of location preferences $\theta$. Our estimate of $\theta$ is close to the point estimate of 11.7 in Allen and Donaldson (2018) and higher than what others have found in the literature. Monte et al. (2018) estimate a preference dispersion parameter of 3.30, and Serrato and Zidar (2016) estimate a parameter between one and two.
} 
amenity values $\bar{u}_{H}$. To do so, we rewrite the two systems of integral equations as follows:

$$
\begin{aligned}
A(i)^{1-\sigma}= & W_{H}^{\frac{1-\sigma}{\delta}} N_{H}^{\frac{\sigma-1}{\delta \theta}} \nu(i)^{1-\sigma} n_{H}(i)^{-1} w_{H}(i)^{-1} b(i) \\
& \times \int_{J} d(i, j)^{1-\sigma} \bar{u}_{H}(j)^{\frac{\sigma-1}{\delta}} C(j)^{\frac{(\sigma-1)(\delta-1)}{\delta}} n_{H}(j)^{\frac{1-\sigma+\delta \theta}{\delta \theta}} w_{H}(j)^{\frac{\sigma-1+\delta}{\delta}} b(j)^{-1} d j \\
\bar{u}_{H}(i)^{\frac{1-\sigma}{\delta}}= & W_{H}^{\frac{1-\sigma}{\delta}} N_{H}^{\frac{\sigma-1}{\delta \theta}} n_{H}(i)^{\frac{1-\sigma}{\delta \theta}} w_{H}(i)^{\frac{\sigma-1}{\delta}} C(i)^{\frac{(\sigma-1)(\delta-1)}{\delta}} \\
& \times \int_{J} d(j, i)^{1-\sigma} A(j)^{\sigma-1} \nu(j)^{1-\sigma} d j
\end{aligned}
$$

Here, $A(i)$ and $\bar{u}_{H}(i)$ are unknown variables, whereas population and wages are known. As long as trade costs are symmetric $d(i, j)=d(j, i)$, we can further reduce the two systems of equation into one. If either of above integral equations hold along with the following relation, then both systems will hold:

$$
\bar{u}_{H}(i)^{\frac{\sigma-1}{\delta}} C(i)^{\frac{(\sigma-1)(\delta-1)}{\delta}} n_{H}(i)^{\frac{1-\sigma+\delta \theta}{\delta \theta}} w_{H}(i)^{\frac{\sigma-1+\delta}{\delta}} b(i)^{-1}=\lambda A(i)^{\sigma-1} \nu(i)^{1-\sigma},
$$

where $\lambda>0$ is a constant. The numerical algorithm by which we solve these equations is described in detail in Appendix D.

Step 2. We use our recovered productivities $A(i)$ to estimate common agglomeration parameter $\alpha$ and to recover base productivities $\bar{A}(i)$. Taking logs of (7) we get:

$$
\log A(i)=\alpha \log n(i)+\log \bar{A}(i)
$$

We regress recovered log total factor productivity on log population, instrumenting population with our estimated high-skill amenity values $\bar{u}_{H}(i)$. Results are reported in Table 6 . We find that the elasticity of Hicks-neutral productivity with respect to population is 0.305 . The IV and OLS results are similar. While not reported, removing population weights barely changes these estimates.

Our estimate is broadly in line with the estimates of other recent quantitative economic geography models, for example, Giannone (2017) finds a common agglomeration elasticity of 0.31. Estimates in the urban and macro literature, on the other hand, are typically less than 0.10 (see the survey by Rosenthal and Strange (2004)). The lower agglomeration elasticity in the urban and macro literature is caused by the assumption that goods produced in different locations are perfect substitutes, i.e. $\sigma$ is infinity. In contrast, we assume a finite elasticity of substitution across goods differentiated by location. If goods produced in different locations are imperfect substitutes, demand falls less when productivity is low. Thus, relative to the case of perfect substitutability, producers in a smaller city are in a better position to compete with producers in larger cities. To explain the data, our model must therefore assign a larger productivity advantage to larger cities. 


\begin{tabular}{lll}
\hline \hline \multicolumn{3}{c}{ Dependent variable: Log productivity } \\
& OLS & IV \\
\hline Log population & $0.319^{* * *}$ & $0.321^{* * *}$ \\
Constant & $-3.049^{* * *}$ & $-3.065^{* * *}$ \\
\hline 1st stage F (CD) & & 59000 \\
1st stage F (KP) & & 3434 \\
Obs & 1267 & 1267 \\
\hline
\end{tabular}

Note: Robust standard errors. All observations are weighted by population. ${ }^{* * *} \mathrm{p}<0.01,{ }^{* *} \mathrm{p}<0.05$, $^{*}$ $\mathrm{p}<0.1$.

Table 6: Estimating agglomeration

At the calibrated values of $\bar{A}$ and $\bar{u}_{H}$, our solution algorithm reproduces the exact data on wages and population of low- and high- skill workers. This cheek confirms the accuracy of both our calibration and simulation algorithms.

\subsubsection{Results for the productivity and amenity shifters}

In Figure 3, we present the estimated geographical distribution of the four exogenous shifters: base productivity, high-skill amenities, relative productivity, and relative amenity valuation.

We estimate that common base productivity is higher in the coastal regions of the United States as well as the Rocky Mountains. It is worth pointing out that, unlike Allen and Arkolakis (2014), we do not find that cities are fundamentally more productive than other regions. ${ }^{30}$ Here we avoid to some degree the critique of the new economic geography literature that cities are exogenously more productive than nearby, naturally similar areas. Instead, we find that areas of the United States which are either near the coastline or have low humidity such as the Rocky Mountain region are more fundamentally productive. ${ }^{31}$ We do find, however, that exogenous high-skill amenities $\bar{u}_{H}$ are strongly correlated with city size. Our results are consistent with those of Albouy (2012) who shows that in many ways cities are attractive places to live for reasons not related to productivity.

Turning to the relative measures, we find that both are reasonably smooth across geography. We find that in relative terms, low-skill people prefer to live in the South, and tend to be exogenously more productive in the Lower Midwest region, possibly reflecting the relatively high soil quality in that region. High-skill people prefer to live in the Upper Midwest, Mountain regions, and Northwest.

\footnotetext{
${ }^{30}$ Neither do we find them consistently less productive than other regions.

${ }^{31}$ The reader should keep in mind that these estimates are neither observed productivity nor amenities. Those objects are functions of the distribution of population which in turn is an equilibrium object in our model.
} 


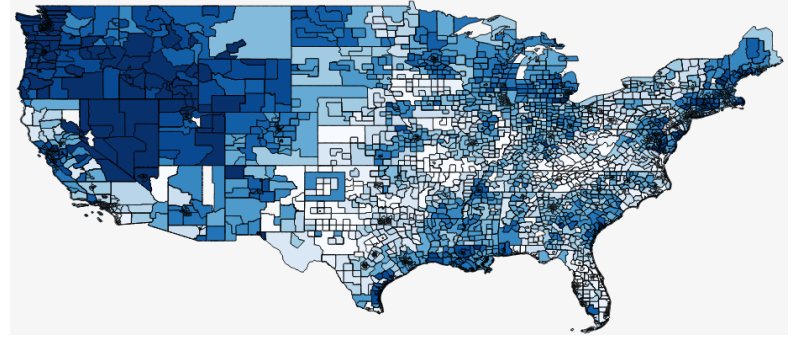

(a) Base common TFP $\bar{A}(i)$

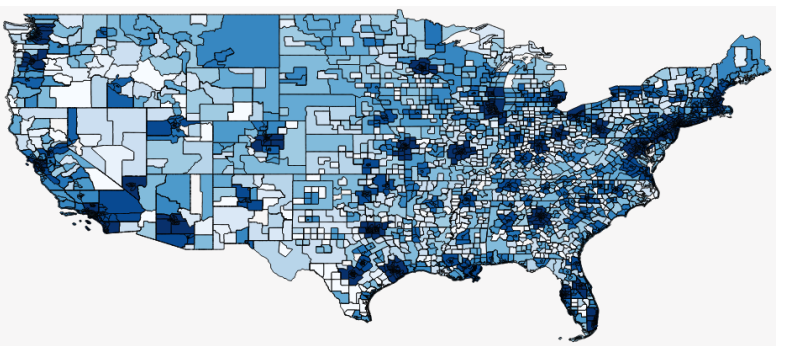

(c) Base high-skill amenities $\bar{u}_{H}(i)$

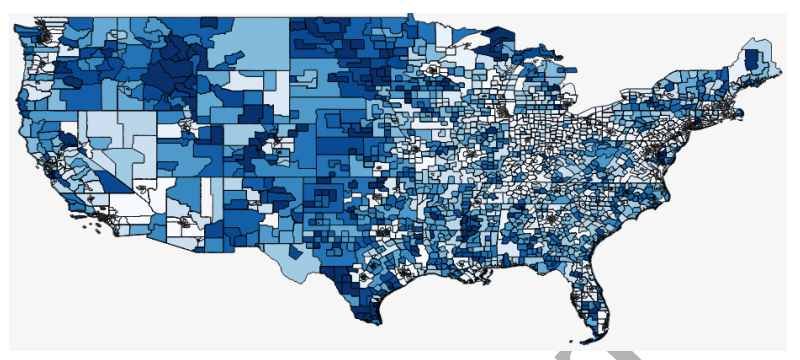

(b) Relative high-skill productivity $\frac{\bar{\beta}_{H}}{\bar{\beta}_{L}}(i)$

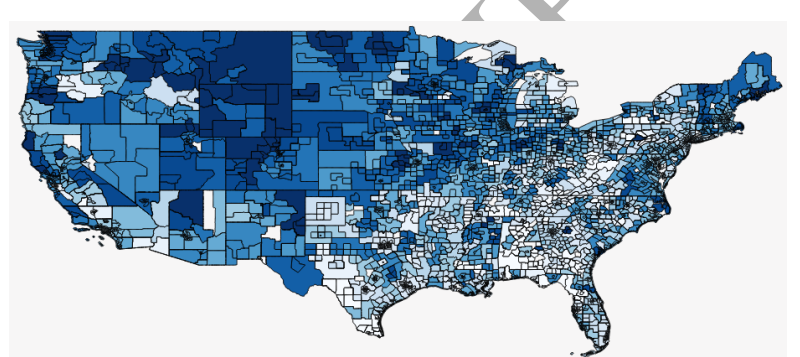

(d) Relative high-skill amenities $\frac{\bar{u}_{H}}{\bar{u}_{L}}(i)$

Figure 3: Locations colored by estimate

\section{Quantitative exercises}

\subsection{Role of geography in skill wage premia}

We motivated our modeling exereise in part as adding geography into a spatial inequality model. To measure the contribution of geography to skill wage premia, we decompose observed variation in skill premia into variations in exogenous base productivities and amenities in absolute and relative terms, as well as geographic position. While our model does not imply a log-linear relationship between these factors and the skill premium, we find that a log-linear reduced-form equation with the exogenous variables and the price index of tradeables on the right-hand-side can explain nearly all the variation in the skill premium. Therefore, we will use the following equation for our decomposition:

$\log \left(\frac{w_{H}(i)}{w_{L}(i)}\right)=\gamma_{1} \log \left(\frac{\bar{\beta}_{H}(i)}{\bar{\beta}_{L}(i)}\right)+\gamma_{2} \log \left(\frac{\bar{u}_{H}(i)}{\bar{u}_{L}(i)}\right)+\gamma_{3} \log \bar{A}(i)+\gamma_{4} \log \bar{u}_{H}(i)+\gamma_{5} \log P(i)+\zeta(i)$

The first four terms on the right hand side are the four exogenous shifters in our model. The fifth term is the tradeables price index $P$. The price index of tradeables in a location exclusively contains information on the geographic position of that location with respect to all other locations because it is the only term that incorporates bilateral trade costs. Lastly, as our model does not imply the above relation in closed form, we include an error term $\zeta$. 


\begin{tabular}{llllrrrrr}
\hline \hline & Notation & Sk. prem & Sk. prem & Shp. $R^{2}$ & Sk. prem & Shp. $R^{2}$ & Sk. prem & Shp. $R^{2}$ \\
\hline Log tradeable price & $P$ & $-0.052^{* * *}$ & $-0.008^{* * *}$ & $16.5 \%$ & & & & \\
Log remoteness & Rem & & & & $-0.053^{* * *}$ & $9.8 \%$ & \\
Log unweighted remoteness & & & & & & \\
Log amenity level & $\bar{u}_{H}$ & & $0.063^{* * *}$ & $15.7 \%$ & $0.067^{* * *}$ & $26.7 \%$ & $0.005^{* * *}$ & $1.4 \%$ \\
Log base productivity & $\bar{A}$ & & 0.002 & $2.4 \%$ & $0.033^{* * *}$ & $2.0 \%$ & $0.004^{* *}$ & $30.4 \%$ \\
Log relative productivity & $\overline{\bar{\beta}}_{H}$ & & $0.228^{* * *}$ & $10.0 \%$ & $0.242^{* * *}$ & $8.1 \%$ & $0.227^{* * *}$ & $7.5 \%$ \\
Log relative amenities & $\overline{\bar{u}}_{H}$ & & $-0.826^{* * *}$ & $55.3 \%$ & $-0.800^{* * *}$ & $53.3 \%$ & $-0.830^{* * *}$ & $58.6 \%$ \\
\hline Observations & $\bar{u}_{L}$ & & 1267 & & 1267 & & 1267 & \\
R-squared & & 1267 & 1.000 & & 0.991 & \multicolumn{1}{c}{} \\
\hline
\end{tabular}

Note: Regressions report robust standard errors. All observations are weighted by population. $* * * \mathrm{p}<0.01, * * \mathrm{p}<0.05,{ }^{*} \mathrm{p}<0.1$.

Table 7: Decomposition

We use this relationship to quantify how much the full matrix of estimated trade costs across all pairs of American cities explains the variations in skill wage premia. In the first column of Table 7 , we report $R^{2}$ for a simple regression of the log skill wage premium on the log price index of tradeables. We find that the price index alone ean explain $30 \%$ of the variations in skill wage premia.

In the third column of Table 7, we report results from the full decomposition. Our RHS variables explain $99.2 \%$ of the observed variations in skill wage premia. Using Shapley decomposition method, we find that $16.5 \%$ of the observed variation in skill wage premia are due to variation in geographic features across American cities. Geographic features explain more of the variation in skill premia than relative productivity and productivity levels combined. While both the variation in geography and productivity contribute measurably to the variation in skill wage premia across space, we find that the largest part of the variation in skill premia is explained by variation in relative amenities. The signs of each factor in the regression are as expected. We expect more productive and nicer places, all else equal to have higher population and thus higher skill premia. We expect more remote places to have lower skill premia. We also expect places with higher relative productivity to have more inequality. Finally, we expect places which high-skill workers value more to have lower skill premia, since high-skill workers will be relatively attracted to these places even if their wages there are relatively low.

In the last four columns of Table 7, we report two similar decompositions, but with the price index replaced by the remoteness measure from Section 2.2 and an unweighted version of the remoteness measure, which is simply an unweighted average of iceberg trade costs. Results are similar across decompositions, although geography explains less of the variation in skill premium when we use remoteness, and even less when we use the unweighted version of remoteness. This is expected, because the price index is the model-consistent weighted average of trade costs. The population weights in the remoteness measure do not fully reflect relevant productivity differences between cities. The unweighted remoteness measure weights all trade costs the same way, but having low trade costs with a productive city is important, while having low trade costs with an unproductive city is irrelevant. 


\subsection{Domestic trade and inequality}

We examine how welfare inequality reacts to changes in domestic trade costs. To highlight the forces at work, we increase trade costs to five times the estimated level. This experiment approximates the standard exercise in the international trade literature of measuring the welfare changes of moving from the observed level of trade to autarky. Although this counterfactual experiment is extreme, it allows us to compare our results with those in the literature. In this exercise, we ask not only how much aggregate welfare decreases, but also how much relative welfare of high to low-skill workers changes.

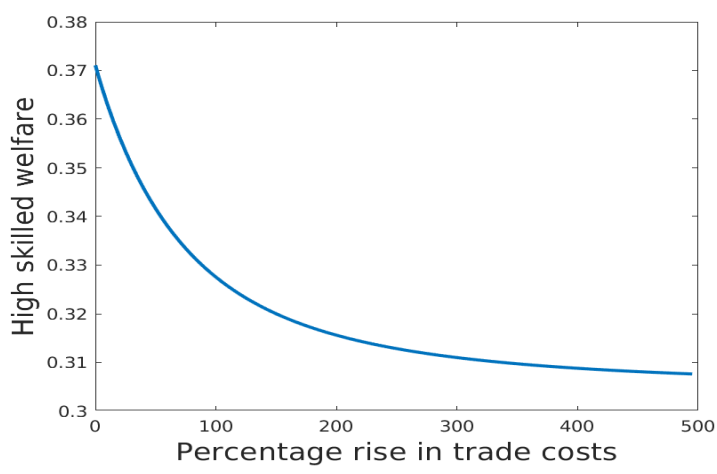

(a) High-skill welfare

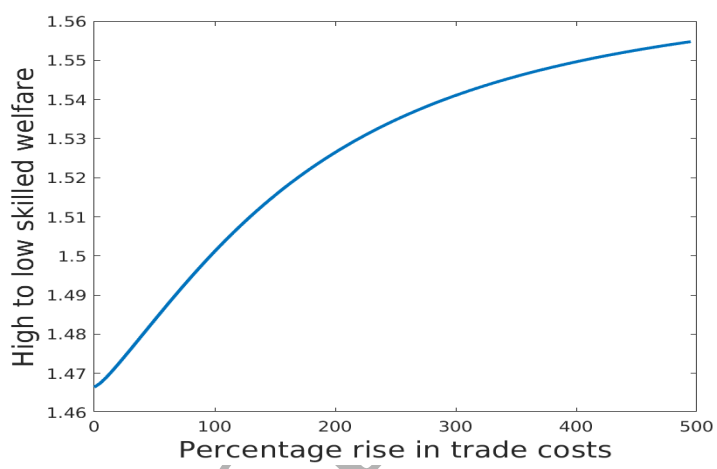

(c) Relative high to low-skill welfare

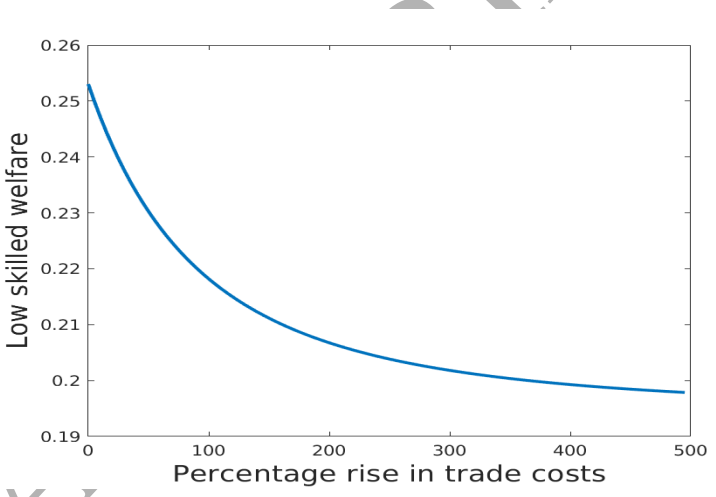

(b) Low-skill welfare

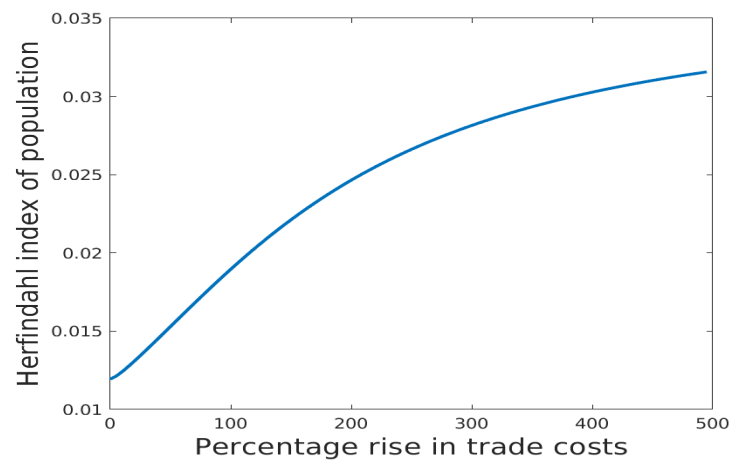

(d) Herfindahl index of population

Figure 4: Trade cost experiments

It is not immediately obvious how we should expect population to change after an increase in trade costs. One force causes additional concentration. After trade costs increase, cheap goods from productive cities are no longer cheap in small towns, and conversely, already expensive goods produced in small towns become even more expensive in cities. This mechanism encourages workers to move to cities in order to access cheap goods and find lucrative jobs, leading to an overall concentration of population and thus an increase in agglomeration forces. Since high-skill workers benefit relatively more from agglomeration, the concentration in population raises welfare inequality. A second force tends to make population diffuse. If trade costs ap- 
proach infinity, all cities are equally isolated. The decrease in the cost advantage of formerly well-connected cities encourages workers to move to formerly isolated cities to benefit from lower housing costs there. This diffusion leads to a lessening of the strength of agglomeration forces and drives welfare inequality down.

We find that the force causing concentration dominates. Figure 4 summarizes our results from a large number of counterfactual experiments. In each experiment we increase all trade costs from their baseline values uniformly by $1,2, \ldots, 500$ percent. Our basic finding is that both high and low-skill welfare fall with increases in trade costs, but low-skill welfare falls more. In the extreme case of five times measured trade cost, high and low-skill welfare decrease by $17.1 \%$ and $21.8 \%$ respectively. Accordingly, the ratio of high to low-skill welfare increases by $6.0 \%$. To make a connection to the intuition we provided above, we also report changes to a Herfindahl index in population, that is, the sum of squared population shares of American cities. As shown in Figure 4, the Herfindahl index in population monotonically increases with trade costs.

In addition to the overall effects on welfare, our model allows us to analyze exactly which areas of the United States grow and shrink as trade costs rise. ${ }^{32}$ Figure 5 contains percentage population changes relative to our data when all trade costs are 500 percentage higher. Blue indicates an increase in population (light greater than 5\%, and dark greater than 25\%), white indicates no change $(-5 \%$ to $5 \%$ population growth), and red indicates a decrease in population (light greater than $5 \%$, and dark greater than $25 \%$ ). Population concentrates in a small number of cities and their surrounding areas across the United States. ${ }^{33}$

We find that population moves away from the formerly well-connected areas in the South and Midwest regions of the United States to the coasts. In particular, the formerly less connected cities Seattle and Portland in the Pacific Northwest expand markedly. Conversely, formerly highly connected cities with lower amenity levels, such as St. Louis or Cincinnati, largely shrink. The five cities with the highest and the five cities with the lowest changes in population are listed in Table 8. ${ }^{34}$ Also in Table 8, we calculate the elasticities of high and low-skill population to a uniform increase in trade costs at the initial level. As a rule, high-skill population is more sensitive to changes in trade costs. As cities grow skilled workers become relatively more productive, inducing more skilled in-migration. As cities shrink skilled workers become relatively less productive, inducing more skilled out-migration.

We have argued that rising trade costs both lead to concentration in large cities, and dispersion away from well-connected cities. Since people prefer to live in well-connected cities, these two variables are highly positively correlated. We provide evidence for these two mechanisms by first regressing log initial population on the log initial price index of tradeables. A city with a low residual from this regression is more well-connected than we might expect given its population. We would expect the dispersion force to dominate in such a city, and the population

\footnotetext{
${ }^{32}$ We can also examine changes to employment ratios and skill premia across cities. These closely track changes to population so that the maps do not qualitatively differ from that presented here on total population changes.

${ }^{33}$ Surrounding areas grow because although trade costs are very high, they are not infinite.

${ }^{34}$ Locations are only included in this table if their total population of high school graduates and 4-year college degree is greater than 300,000 in the data.
} 
to fall. The opposite is true for a city with a high residual. We would expect the concentration force to dominate and the city to grow. Figure 6 is a scatter plot of log population change against the residual from the regression described above. The circle size is proportional to the initial population of the city. As predicted we see a positive slope, indicating that population falls more on average in cities with low residuals.

These results complement a literature that studies the effects of international trade on inequality in developing countries (Antràs et al., 2006; Hummels et al., 2014). In contrast to the Stolper-Samuelson theorem, globalization has increased inequality even in developing countries (Davis and Mishra, 2007). We find instead that domestic trade costs and inequality are positively correlated. The key difference in our context is that workers are mobile, and thus agglomeration economies change endogenously with market integration. The negative effect of trade on the skill wage premium in the international context is reversed when labor is mobile across locations within a nation.

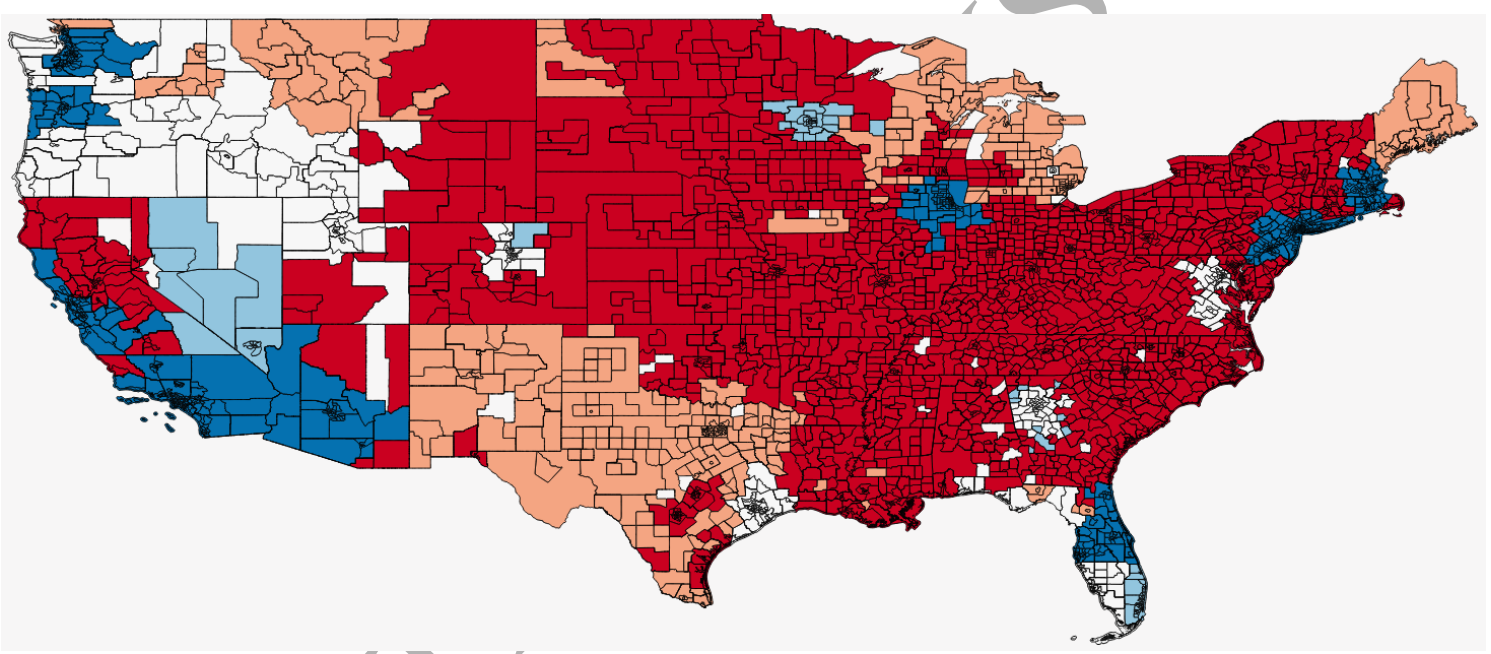

Figure 5: Population changes when all trade costs are five times larger

Note: Blue: increase in population, White: no or little growth, Red: decrease in population.

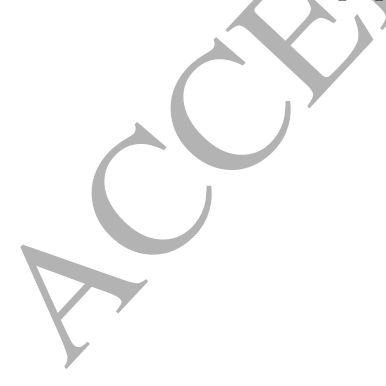




\begin{tabular}{lccccc}
\hline & \multicolumn{2}{c}{$500 \%$ trade cost } & \multicolumn{2}{c}{ Elasticity at Initial Pop } \\
\hline City & $\begin{array}{c}\text { baseline working } \\
\text { population (million) }\end{array}$ & $\begin{array}{c}500 \% \text { t.c. working } \\
\text { population (million) }\end{array}$ & $\begin{array}{c}\text { \% change } \\
\text { high-skill } \\
\text { pop elasticity }\end{array}$ & $\begin{array}{c}\text { low-skill } \\
\text { pop elasticity }\end{array}$ \\
\hline Philadelphia & 1.0 & 2.0 & $105 \%$ & 0.34 & 0.27 \\
New York City & 2.7 & 5.5 & $105 \%$ & 0.33 & 0.27 \\
Seattle & 0.5 & 1.0 & $103 \%$ & 0.33 & 0.27 \\
San Bernardino & 0.4 & 0.7 & $83 \%$ & 0.33 & 0.27 \\
Los Angeles & 1.5 & 2.7 & $82 \%$ & 0.32 & 0.26 \\
\hline Cleveland & 0.4 & 0.2 & $-33 \%$ & -0.12 & -0.04 \\
St. Louis & 0.4 & 0.2 & $-45 \%$ & -0.27 & -0.15 \\
Pittsburgh & 0.4 & 0.2 & $-46 \%$ & -0.22 & -0.12 \\
Kansas City & 0.3 & 0.2 & $-47 \%$ & -0.30 & -0.18 \\
Cincinnati & 0.3 & 0.2 & $-51 \%$ & -0.19 & -0.09 \\
\hline
\end{tabular}

Table 8: The five top regions with the highest and the top five with the lowest counterfactual population growth (reported for locations initially larger than 300,000 high school and college workers)

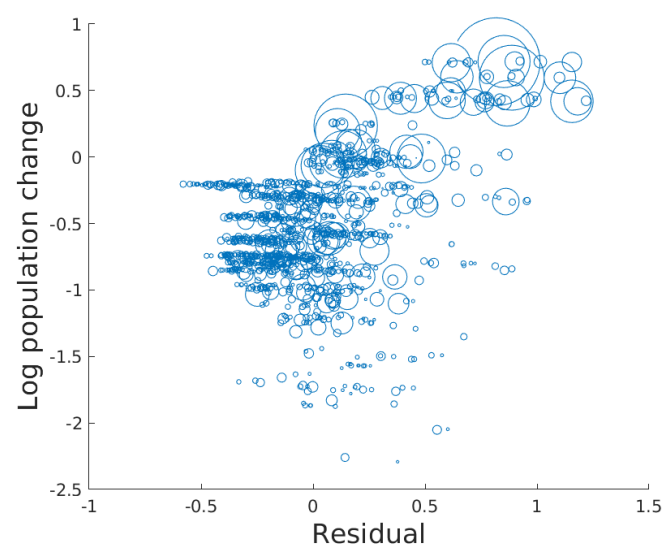

Figure 6: Log population change against residual of log initial population on log price index

\subsection{Californian productivity shocks}

In the 20 years leading up to the turn of the 21st century, California's share of the US population increased by 1.8 percentage points. In the same period, the skill employment ratio in California grew by 14 percentage points. ${ }^{35}$ The growth in California's population and its biased growth

\footnotetext{
${ }^{35}$ The US population share of California grew from $10.2 \%$ in 1980 to $12.0 \%$ in 2000 . Put another way, California's population increased by $43.1 \%$ from 1980 to 2000, while the total population of the United States increased by only $19.3 \%$. The college population share in California was $37 \%$ in 1980 and $51 \%$ in 2000 .
} 
in highly educated workers were the outcome of nontrivial interactions between productivity, demographics, housing regulations and other factors both in California and in other states. That being said, one particularly important factor behind Californian growth in this period was the expansion of the computing and high technology sectors. This period saw the rise of Silicon Valley during the lead up to the Dot-Com Bubble.

\begin{tabular}{lcc}
\hline \hline Average national high-skill welfare & & 1.3 \\
Average national low-skill welfare & & 0.3 \\
Average national welfare ratio & California & Rest of the United States \\
& 11.4 & -0.4 \\
High-skill wages & 7.4 & -1.1 \\
Low-skill wages & 3.4 & 0.7 \\
Skill premium & 42.9 & -4.0 \\
High-skill population & 3.9 & -0.4 \\
Low-skill population & -5.0 & -0.7 \\
Price of tradeables & 6.9 & -1.4 \\
Total price index & 4.0 & 1.0 \\
High-skill real wages & 0.6 & 0.3 \\
Low-skill real wages & & \\
\hline
\end{tabular}

Table 9: The effects of California's productivity shocks on welfare, prices, and wages (percentage change)

We perform a counterfactual exercise to study how technological progress in California contributed to welfare and inequality in California and across the United States. Holding the rest of the United States constant, we scale up the total factor productivity $\bar{A}$ and the skill bias of technology $\bar{\beta}_{H} / \widehat{\beta}_{L}$ in all regions in California proportionally to match the observed growth in Californian population share and the growth in the skill employment ratio. We find that the skill bias of Californian technology rose by $8.8 \%$ and Californian total factor productivity increased by $9.0 \%$ from 1980 to 2000.

We report other results of this counterfactual exercise as percent changes from the counterfactual case to our baseline in Table 9 . We find that the national expected welfare of high-skill workers increased by $1.3 \%$, the national expected welfare of low-skill workers increased by $0.3 \%$, and welfare inequality rose by $1.0 \%$.

Furthermore, we examine changes to wages and prices across locations within a skill group, and across skill groups within a location. Table 9 reports changes to the population-weighted mean wages, prices, and skill premium in California and the rest of the United States. Overall, the skill premium rose an average by $3.4 \%$ across Californian cities, and $0.7 \%$ on average elsewhere. The skill premium in California increased less than the skill bias of technology. We might have expected the opposite, since the effect of exogenous high-skill productivity increases 
on the skill wage premium could be amplified through population growth and the accompanying high-skill agglomeration advantage. On the other hand, general equilibrium effects act to dampen the effect of productivity changes by increasing the supply of high-skill workers in California. In addition, the overall price index including both housing and tradeables rose by $6.9 \%$ in California while it fell by $1.4 \%$ elsewhere. In California, the higher price index is due to a dramatic increase in housing prices which dominate the fall in the price of tradeables, while in the rest of the US cheaper tradeables are the main driver of the lower cost of living.

\section{$6 \quad$ Extensions}

In this section, we discuss a few ways of extending our results.

Sorting into industries and occupations. We have shown that more centrally located cities tend to have higher skill wage premia. We look into how geographic location would matter for skill premia through sorting of skills into industries and ócupations. To provide suggestive evidence, we add industry- and occupation-related controls to our individual-level regressions in Section 2. We classify all industries into 30 groups and all oecupations into 23 groups based on IPUM classifications (see Table 11 in the appendix). We then define skill intensity for an industry (or occupation) as the share of college employment in that industry (or occupation) at the national level. Table 10 reports our regressions results. In column (1) we include industry and occupation fixed effects. In column (2) we instead control for industry and occupation skill intensity. In column (3), we reproduce column (5) of Table 2 where we allow for college dummy interacted with remoteness and population without controlling for industry or occupation. In column (4), we also allow industry and occupation skill intensity to interact with population and remoteness. As in Table 2, we are mainly interested in the coefficient on the interaction of college dummy with remoteness, which reflects how large wages of college graduates are compared to high-school graduates in more remote cities.

Geographic location of a city remains correlated with skill premia across all specifications. The coefficient of remoteness interacted with college slightly decreases from -0.113 in column (3) to -0.094 in column (4) where we add industry and occupation controls. ${ }^{36}$ We take this as suggestive evidence that sorting to industries and occupations may mediate the relationship between remoteness and skill wage premia, but only marginally.

\footnotetext{
${ }^{36}$ Furthermore, the coefficient of remoteness for high-school graduates is not statistically significant in column (4), suggesting that once industry and occupation are controlled for, the remoteness effect operates primarily through college graduates.
} 
dependent variable: log wage of individual workers

(1)

Log remoteness

College

Log population

Ind skill intensity

Occ skill intensity

College X Log remoteness

Ind skill intensity X Log remoteness

Occ skill intensity X Log remoteness

College X Log population

Ind skill intensity X Log population

Occ skill intensity X Log population

\begin{tabular}{lcccc} 
R-squared & 0.357 & 0.293 & 0.276 & 0.296 \\
Ind \& Occ FE & $\mathrm{Y}$ & $\mathrm{N}$ & $\mathrm{N}$ & $\mathrm{N}$ \\
\hline
\end{tabular}

Notes: Standard errors, clustered at city level, are reported in parentheses. In all regressions, there are 3,050,723 observations, we weight individuals based on census sampling weights, and wê include individual-level gender and race dummies, a cubic polynomial of years of experience, and state fixed effects. *** $\mathrm{p}<0.01, * * \mathrm{p}<0.05,{ }^{*} \mathrm{p}<0.1$.

Table 10: Wages and remoteness controlling for industry and occupation, at the level of individual workers

Endogenous skill-biased amenities. Amenities might endogenously respond to skill composition of a city, as discussed in Diamond (2015), and low and high-skill workers may value these amenities differently. In an extension of our model, we specify amenities as $u_{s}(i)=\bar{u}_{s}(i)\left[\frac{n_{H}(i)}{n_{L}(i)}\right]^{\eta_{s}}$ where $\eta_{s}$ captures the degree to which skill composition affects the supply of amenities. Including this specification into relative supply equation (13), and combining with relative demand 
equation (12) gives

$$
\frac{w_{H}(i)}{w_{L}(i)}=\left(\frac{W_{H}}{W_{L}}\right)^{\frac{\theta}{\theta+\tilde{\rho}}}\left(\frac{\bar{u}_{H}(i)}{\bar{u}_{L}(i)}\right)^{\frac{-\theta}{\theta+\tilde{\rho}}}\left(\frac{N_{H}}{N_{L}}\right)^{\frac{-1}{\theta+\widetilde{\rho}}}\left(\frac{\bar{\beta}_{H}(i)}{\bar{\beta}_{L}(i)}\right)^{\frac{\tilde{\rho}}{\theta+\widetilde{\rho}}} n_{H}(i)^{\frac{\varphi \tilde{\rho}}{\theta+\tilde{\rho}}}
$$

where $\widetilde{\rho} \equiv \rho\left(1-\theta\left(\eta_{H}-\eta_{L}\right)\right)$. This equation, as an equilibrium relationship in relative terms, collapses to equation (14) if $\eta_{H}-\eta_{L}=0$. We examine how our parameter estimates change in this extended model. On the one hand, we rewrite our estimable equation (22),

$$
\tilde{w}(i)=\tilde{\kappa}+\frac{1-\theta\left(\eta_{H}-\eta_{L}\right)}{\theta} \tilde{n}(i)-\tilde{u}(i)
$$

The instrumental variables strategy used to estimate the dispersion of location preferences the relative supply equation (22) should still remain valid for estimating (29). In this endogenous amenities version of the model, however, we interpret the estimate differently. In particular, the estimated coefficient $\tilde{n}(i), 0.072$, implies that $\theta=\frac{1}{0.072+\left(\eta_{H}-\eta_{L}\right)}$. Suppose $\eta_{H}>\eta_{L}$ meaning that high-skill workers attach a higher valuation to amenities derived from relative supply of highskill workers. Then, relative to our baseline estimates, we would infer a smaller $\theta$. That is, we would estimate more dispersion in unobserved location preferences. Intuitively, the labor supply equations describe the way that the relative supply of high-skill workers reacts to the relative wage. This is informative about worker preferences over locations, because the more indifferent they are between locations, the more population will react to wage level. Since endogenous amenities increase the incentive for high-skill workers to live in cities with a high relative supply of high-skill workers, to explain the observed relationship between relative wages and relative population we do not need workers to be as indifferent between locations as in our baseline model.

Since $\eta_{s}$ does not enter into relative demand equation (23), we will have the same estimates of $\rho$ and $\varphi$ as in our baseline. Substituting these expressions into equation (28), we find that the exponent of $n_{H}$ in the extended model is exactly the same as that in equation (14) in our baseline model. Hence, the estimated elasticity of the wage premium to high-skill employment will remain unchanged. On the other hand, our estimates of the fundamental productivity and amenity shifters would be somewhat different in a version of the model with endogenous amenities. The key challenge in such an exercise would be to devise a model-consistent estimation method to separate the elasticity parameters $\eta_{s}$ from the location dispersion parameter $\theta$.

Migration costs. In this paper we have developed a medium-run static model building on an empirical spatial equilibrium literature. Geography enters our model purely through trade costs. Another potential way in which geography might affect the distribution of wages is through migration costs. For example, if it is more costly to move far away, then initial placement will be an important determinant of final location choice. Since our model is static and we are considering medium-run outcomes, in our baseline we abstract from dynamic frictions like 
moving costs. ${ }^{37}$ Several studies on China using similar static models in the spatial equilibrium tradition have developed methods by which to include some sense of moving cost (Fan, 2019; Tombe and Zhu, 2019). This exercise is of critical importance in studying China, as the hukou system permanently reduces the public services available to migrants, particularly people born in the countryside wishing to move to the city. Consistent with the Chinese context, migration costs in for example Tombe and Zhu (2019) are modeled not as a one-time cost of relocation, but rather as a flow cost which substantially scales down welfare according to their estimates. ${ }^{38}$ If relocation costs are less substantial and paid once at the time of moving, as we might presume about the American context we study, then in the medium-run they are likely less important than they are in China.

Although we do not include moving costs in our baseline model, we can speculate how large flow costs as in Tombe and Zhu (2019) might affect our results. It is easiest to consider the case in which moving costs are uniform across skill groups, and are paid only if a worker currently lives in a location other than where he is born. There will be an intuitive trade off between the dispersion of preferences over cities and moving costs. The higher are moving costs, the higher will $\theta$ need to be in order to rationalize the observed spatial distribution of workers. Since moving costs and preference dispersion both discourage movement, counterfactual population flows in response to productivity or policy shocks may be comparable in such an extension to our baseline results.

\section{Conclusion}

We document that isolated cities tend to have lower skill wage premia. We develop a theory in which the higher cost of tradeables in isolated cities makes them less attractive to live in, and high-skill workers are less productive in smaller cities. We build a quantitative model to understand and measure this mechanism. Our model bridges the gap between the spatial inequality literature which abstracts from geography, and the economic geography literature, which abstracts from inequality. We find that $16.5 \%$ of observed variations in skill wage premium is due to the geographic location of cities. In addition, we find that a uniform increase in domestic trade costs causes/welfare inequality to rise due to the interaction between a higher concentration of population and the agglomeration advantage of high-skill labor. In a counterfactual experiment, we find that the rise of Silicon Valley increased the skill wage premium in California by $3.4 \%$ and welfare inequality across the United States by $1.0 \%$.

${ }^{37} \mathrm{~A}$ recent literature has developed dynamic spatial models more suited to studying dynamic frictions. Kennan and Walker (2011) use a dynamic discrete choice model to understand the role of learning and moving costs in US interstate migration. Caliendo et al. (2018) develop a dynamic equilibrium model to understand how trade reforms interacted with population movement in the European Union.

${ }^{38}$ Tombe and Zhu (2019) specify migration costs as proportional to destination welfare, analogously to how iceberg trade costs are specified as proportional to origin price. They estimate that these iceberg welfare costs of migration are on average 2.8 in 2000 across Chinese province pairs. To get a sense of the magnitude of these costs we can compare them with their trade counterpart. Anderson and Van Wincoop (2004) report iceberg trade costs across US states to be around 1.7 on average. 


\section{References}

Acemoglu, D. and Autor, D. (2011). Skills, tasks and technologies: Implications for employment and earnings. In Handbook of labor economics, volume 4, pages 1043-1171. Elsevier.

Aguiar, M. and Bils, M. (2015). Has consumption inequality mirrored income inequality. American Economic Review, 105:2725-2756.

Albouy, D. (2012). Are big cities bad places to live? estimating quality of life across metropolitan areas. mimeograph.

Allen, T. and Arkolakis, C. (2014). Trade and the topography of the spatial economy. The Quarterly Journal of Economics, 129(3):1085-1140.

Allen, T., Arkolakis, C., and Li, X. (2016). Optimal city structure. mimeograph.

Allen, T. and Donaldson, D. (2018). The geography of path dependence. Technical report, Working Paper.

Anderson, J. E. and Van Wincoop, E. (2004). Trade costs. Journal of Economic literature, 42(3):691-751.

Antràs, P., Garicano, L., and Rossi-Hansberg, E. (2006). Offshoring in a knowledge economy. Quarterly Journal of Economics, 121(1)

Bacolod, M., Blum, B. S., and Strange, W. C. (2009). Skills in the city. Journal of Urban Economics, 65(2):136-153.

Bartelme, D. (2018). Trade costs and economic geography: evidence from the us. Working Paper.

Bartik, T. J. (1991). Boon or boondoggle? the debate over state and local economic development policies.

Baum-Snow, N., Ereedman, M., and Pavan, R. (2018). Why has urban inequality increased? American Economic Journal: Applied Economics, 10(4):1-42.

Baum-Snow, N. and Pavan, R. (2013). Inequality and city size. Review of Economics and Statistics, 95(5):1535-1548.

Broda, C. and Weinstein, D. E. (2006). Globalization and the gains from variety. The Quarterly journal of economics, 121(2):541-585.

Caliendo, L., Opromolla, L. D., Parro, F., and Sforza, A. (2018). Goods and factor market integration: a quantitative assessment of the eu enlargement. Technical report, National Bureau of Economic Research. 
Card, D. (2009). Immigration and inequality. The American Economic Review, 99(2):1.

Ciccone, A. and Peri, G. (2006). Identifying human-capital externalities: Theory with applications. The Review of Economic Studies, 73(2):381-412.

Combes, P.-P., Duranton, G., Gobillon, L., Puga, D., and Roux, S. (2012a). The productivity advantages of large cities: Distinguishing agglomeration from firm selection. Econometrica, $80(6): 2543-2594$.

Combes, P.-P., Duranton, G., Gobillon, L., and Roux, S. (2012b). Sorting and local wage and skill distributions in france. Regional Science and Urban Economics, 42(6):913-930.

Coşar, A. K. and Fajgelbaum, P. D. (2016). Internal geography, international trade, and regional specialization. American Economic Journal: Microeconomics, 8(1):24-56.

Davis, D. R. and Dingel, J. I. (2019). A Spatial Knowledge Economy. American Economic Review, 109(1):153-170.

Davis, D. R. and Mishra, P. (2007). Stolper-samuelson is dead: And other crimes of both theory and data. In Globalization and poverty, pages 87-108. University of Chicago Press.

Desmet, K., Nagy, D. K., and Rossi-Hansberg, E. (2016). The geography of development. Journal of Political Economy.

Diamond, R. (2015). The determinants and welfare implications of us workers diverging location choices by skill: 1980-2000. American Economic Review.

Ellison, G. and Glaeser, E. L. (1999). The geographic concentration of industry: does natural advantage explain agglomeration? American Economic Review, 89(2):311-316.

Fajgelbaum, P. and Gaubert, C. (2018). Optimal spatial policies, geography and sorting. Technical report, National Bureau of Economic Research.

Fajgelbaum, P. D., Morales, E., Suárez Serrato, J. C., and Zidar, O. (2018). State taxes and spatial misallocation. The Review of Economic Studies, 86(1):333-376.

Fan, J. (2019). Internal geography, labor mobility, and the distributional impacts of trade. American Economic Journal: Macroeconomics, forthcoming.

Farrokhi, F. (2018). Skill, agglomeration, and inequality in the spatial economy. Technical report.

Fujita, M., Krugman, P. R., and Venables, A. (2001). The spatial economy: Cities, regions, and international trade. MIT press.

Fujita, M. and Thisse, J.-F. (2006). Globalization and the evolution of the supply chain: Who gains and who loses? International Economic Review, 47(3):811-836. 
Gaubert, C. (2018). Firm sorting and agglomeration. American Economic Review, 108(11):311753.

Giannone, E. (2017). Skilled-biased technical change and regional convergence. Technical report, University of Chicago Working Paper.

Glaeser, E. L. and Resseger, M. G. (2010). The complementarity between cities and skills*. Journal of Regional Science, 50(1):221-244.

Goldin, C. D. and Katz, L. F. (2009). The race between education and technology. Harvard University Press.

Gould, E. D. (2007). Cities, workers, and wages: A structural analysis of the urban wage premium. The Review of Economic Studies, 74(2):477-506.

Hummels, D., Jørgensen, R., Munch, J., and Xiang, C. (2014). The wage effects of offshoring: Evidence from danish matched worker-firm data. The American Economic Review, 104(6):1597-1629.

Hummels, D. and Lee, K. Y. (2018). The income elasticity of import demand: Micro evidence and an application. Journal of International Economics, 113:20-34.

Katz, L. F. et al. (1999). Changes in the wage structure and earnings inequality. Handbook of labor economics, 3:1463-1555.

Kennan, J. and Walker, J. R. (2011). The effect of expected income on individual migration decisions. Econometrica, $79(1): 211-251$.

Krugman, P. (1980). Scale economies, product differentiation, and the pattern of trade. The American Economic Review, 70(5):950-959.

Krugman, P. (1991a). History and industry location: the case of the manufacturing belt. The American Economic Review, 81(2):80-83.

Krugman, P. (1991b). Increasing returns and economic geography. The Journal of Political Economy, 99(3):483-499.

Lindley, J. and Machin, S. (2014). Spatial changes in labour market inequality. Journal of Urban Economics, 79:121-138.

Matano, A. and Naticchioni, P. (2011). Wage distribution and the spatial sorting of workers. Journal of Economic Geography, 12(2):379-408.

McCarty, N., Poole, K. T., and Rosenthal, H. (2016). Polarized America: The dance of ideology and unequal riches. mit Press. 
Monte, F., Redding, S. J., and Rossi-Hansberg, E. (2018). Commuting, migration, and local employment elasticities. American Economic Review, 108(12):3855-90.

Moretti, E. (2013). Real wage inequality. American Economic Journal: Applied Economics, $5(1): 65-103$.

Rosenthal, S. S. and Strange, W. C. (2004). Evidence on the nature and sources of agglomeration economies. Handbook of regional and urban economics, 4:2119-2171.

Serrato, J. C. S. and Zidar, O. (2016). Who benefits from state corporate tax cuts? a local labor markets approach with heterogeneous firms. The American Economic Review, 106(9):25822624 .

Simonovska, I. and Waugh, M. E. (2014). The elasticity of trade: Estimates and evidence. Journal of international Economics, 92(1):34-50.

Tombe, T. and Zhu, X. (2019). Trade, migration and productivity: A quantitative analysis of china. American Economic Review, forthcoming.

US Census (2012). 2010 census summary file 1: Technical documentation. http://www.census.gov/prod/cen2010/doc/sf1.pdf.

US Census (2019). Commodity flow survey. https://www.census.gov/programssurveys/cfs.html. Accessed: 2019-03.

US Environmental Protection Agency (2019). Air quality data. https:/www.epa.gov/outdoorair-quality-data. Accessed: 2019-01.

US National Oceanic and Atmospheric Administration (2016). Us temperature and humidity raster maps. https://www.chimate.gov/maps-data. Accessed: 2016-09.

Wilkinson, R. G. and Pickett, K. E. (2006). Income inequality and population health: a review and explanation of the evidence. Social science \&f medicine, 62(7):1768-1784.

Ziv, O. (2017). Geography in reduced form. 